\title{
Participación de los sectores agropecuario y de hidrocarburos y minería en el producto interno bruto (PIB) de los países de América del Sur entre 1960 y 2014
}

Pedro Henrique de Abreu Paiva y Carlos José Caetano Bacha

\section{Resumen}

Se analiza la participación de los sectores agropecuario, de hidrocarburos y minería en el PIB de los países sudamericanos entre 1960 y 2014. Si bien la participación del sector agropecuario de los países sudamericanos presenta una tendencia a la baja, se observan aspectos comunes entre tres subgrupos de países. El primero está formado por los países fundadores del MERCOSUR, cuya balanza comercial de productos agropecuarios y agroindustriales fue superavitaria y en los que la participación del sector agropecuario volvió a crecer entre 2002 y 2007 . El segundo subgrupo corresponde a los países andinos, donde la participación del sector agropecuario en el PIB disminuyó desde 1960, mientras la representatividad de la producción de hidrocarburos y minería fue en aumento, especialmente durante la década de 2000. El tercer subgrupo está integrado por Guyana y Suriname, donde la serie histórica de la participación del sector agropecuario presenta una forma de $U$ invertida.

\section{Palabras clave}

Agricultura, minería, hidrocarburos, sector industrial, producción industrial, producto interno bruto, estadísticas agrícolas, estadísticas industriales, América del Sur, MERCOSUR

Clasificación JEL

O13, O57, Q10

\section{Autores}

Pedro Henrique de Abreu Paiva es magíster en economía aplicada de la Universidad de São Paulo y analista de planificación en la Institución de Cooperación Intermunicipal de Paraopeba Media (ICISMEP), Brasil. Correo electrónico: pedroabreupaiva@gmail.com.

Carlos José Caetano Bacha es profesor titular del Departamento de Economía, Administración y Sociología de la Escuela Superior de Agricultura Luiz de Queiroz de la Universidad de São Paulo, Brasil. Correo electrónico: carlosbacha@usp.br. 


\section{Introducción}

La teoría de las ventajas comparativas postula que los países deberían destinar sus recursos productivos (tierra, trabajo y capital) a las actividades de producción y servicios en las que tengan ventajas comparativas de costo en relación con otros países. Esta idea está asociada al hecho de que los capitales extranjeros, según su interés, decidirán qué producir, dónde producir y dónde consumir. Estos dos factores (ventajas comparativas y papel del capital extranjero) definen una división internacional del trabajo que ayuda a explicar, en gran parte, la estructura productiva de los países de América del Sur y el predominio en los últimos años de las actividades agropecuarias, de hidrocarburos y mineras en dicho aparato productivo.

Entre los siglos XVI y XIX, los países de América del Sur fueron explotados como colonias españolas y portuguesas, cuya finalidad principal era proveer a los mercados extranjeros de productos agrícolas y mineros. El papel impuesto a estas colonias limitó el desarrollo de la actividad industrial, haciendo de ellas economías vendedoras de materias primas y compradoras de productos industrializados originados en las metrópolis de la época (Baer, 2008; Furtado, 1989). Esta, claramente, era la división internacional del trabajo que existía entonces.

Ya como países independientes, durante la segunda mitad del siglo XIX y la primera mitad del siglo XX, los países sudamericanos continuaron desarrollando la minería y la actividad agropecuaria como actividades principales. Además de vender dichos productos a los mercados extranjeros, destinaban una parte a satisfacer la mayor demanda interna derivada de una incipiente agroindustrialización. Sin embargo, esas actividades fueron conducidas directa o indirectamente por el capital extranjero, especialmente de origen inglés. El dinamismo productivo estaba determinado por empresas transnacionales propietarias de minas, que también controlaban el comercio internacional, tanto de productos agrícolas como de productos mineros. Esta situación continúa incluso en la actualidad.

Entre 1950 y 1970, las ideas de la Comisión Económica para América Latina y el Caribe (CEPAL) llevaron a los países de América del Sur a estimular sus industrias. No obstante, la mayor parte de esos estímulos se concentró en los recursos naturales y en los productos agrícolas. Estos años se caracterizan por la implementación de políticas proteccionistas, que determinaron la creación de monopolios estatales en la explotación minera y de hidrocarburos y limitaron el acceso del capital extranjero (como en el caso de Petrobras en el Brasil (Baer, 2008)). Aun así, el papel de las empresas transnacionales como principales compradoras de estos productos se mantuvo.

Según Silva, Gómez y Castañeda (2012), en la década de 1990 se comenzó a adoptar el modelo neoliberal en la mayoría de los países latinoamericanos. En varios de ellos (como el Brasil, Chile, Colombia y el Perú) se flexibilizaron las leyes para ampliar la participación del capital extranjero en la explotación directa de los recursos naturales y la exportación se mantuvo como principal destino de esas materias primas (Lagos y Peters, 2010). Desde entonces, además de los capitales europeos y estadounidenses ya operantes, han surgido nuevas empresas financiadas por capitales de otros países interesados en explotar los recursos naturales y la producción agropecuaria en América del Sur, entre ellos China (llyásova y Sérbinov, 2015). La intención detrás de estos nuevos capitales es recibir las materias primas como retribución por la financiación realizada. Según llyásova y Sérbinov (2015, pág. 1), los financiamientos que la República Bolivariana de Venezuela recibió de China desde 2007 para desarrollar su industria petrolera se están pagando en barriles de petróleo. En el caso del Brasil, parte del crédito destinado al sector agropecuario se canaliza a través de empresas extranjeras que conceden préstamos en forma de insumo a cambio de los productos agrícolas que se han de exportar (Bacha, 2012). 
La década de 2000 se ha caracterizado como una nueva fase posneoliberal. Una vez más, el capital extranjero ha invertido en América del Sur, tanto para producir materias primas destinadas principalmente a la exportación como para viabilizar esas exportaciones mediante mejoras en la infraestructura. Una proporción significativa del PIB y de las exportaciones de estos países continúa basándose en productos primarios. Según datos de Belloni y Wainer (2014, pág. 106), esos productos representaron al menos el 68,8\% de las exportaciones argentinas de 2001 a 2011. En el caso del Estado Plurinacional de Bolivia, el Brasil, Chile, Colombia, el Ecuador, el Paraguay, el Perú, el Uruguay y la República Bolivariana de Venezuela estos porcentajes fueron, respectivamente, el $88,7 \%$, el $44,9 \%$, el $80,5 \%$, el $69 \%$, el $91,8 \%$, el $93,1 \%$, el $70,5 \%$, el $79,4 \%$ y el $83,7 \%$.

Mientras en Chile, el Perú y Colombia se optó por una mayor apertura a los capitales extranjeros para la explotación de los recursos naturales, que antes estaban en manos del Estado, en el Brasil, la Argentina y el Uruguay se optó por la propiedad estatal, pero se permitió la participación de capital extranjero en la producción agropecuaria y se otorgaron concesiones para la explotación de hidrocarburos y productos mineros. En el Estado Plurinacional de Bolivia, la República Bolivariana de Venezuela y el Ecuador se tendió, en algunos momentos, a la restricción del capital extranjero vinculado a la explotación de sus recursos naturales y producción agropecuaria, pero no a su prohibición. A pesar de que se puede diferenciar a estos tres grupos de países por la flexibilidad dada al capital extranjero para participar en la explotación de materias primas, dicha explotación aún no ha modificado significativamente las condiciones de vida de las poblaciones sudamericanas (Belloni y Wainer, 2014).

En algunos trabajos se argumenta que en el período de 2002 a 2008 (durante el auge de los precios de los productos básicos) los países de América del Sur sufrieron la enfermedad holandesa, situación en la que los ingresos obtenidos por las exportaciones de materias primas valorizan las monedas locales y estimulan la importación de productos industrializados (Bresser-Pereira y Marconi, 2008, para el Brasil). Otros autores, sin embargo, sostienen que ese fenómeno no se verificó (Puyana y Constantino, 2013, para la Argentina).

Es importante destacar que las economías basadas en la explotación de hidrocarburos y productos mineros podrían tener problemas de sustentación y sostenibilidad en el futuro. Además de que el agotamiento de los recursos naturales no renovables compromete el futuro de esas economías, se observan cuantiosos daños ambientales causados por la contaminación de ríos y otras fuentes hídricas. Aunque la producción agrícola también plantea desafíos ambientales, sus efectos son menores que los de la minería y desempeña un papel importante en la seguridad alimentaria.

Si bien este artículo no se centrará en los temas citados, se procurará mostrar la evolución de las actividades agropecuarias y de explotación minera y de hidrocarburos, resaltando sus distintas trayectorias en los países de América del Sur. Asimismo, se argumentará sobre la manera en que la asignación de los factores de producción puede dar una idea sobre las diferencias en el dinamismo de estas actividades en cada uno de esos países. Aun así, el mayor foco de atención estará en la evolución del sector agropecuario pues, a pesar de su participación cada vez más reducida en el PIB de los países sudamericanos, es importante analizar la forma en que los patrones de esta reducción cambian entre los diferentes países.

Específicamente, el objetivo de este artículo es analizar la evolución de la importancia del sector agropecuario en el PIB de los países de América del Sur y compararla con la importancia de la explotación minera y de hidrocarburos en dichos países. Se espera observar posibles diferencias en la trayectoria de la representatividad porcentual de estos sectores en el PIB entre 1960 y 2014. En ese orden de ideas, dentro de la serie histórica analizada se prestará especial atención a la década de 2000, pues en dicho período muchos países de la región resultaron fuertemente beneficiados por el auge de los precios de los productos básicos mineros y agropecuarios. 
Las actividades agrícolas compiten con la explotación minera y de hidrocarburos por la asignación de tierras, infraestructura, capital invertido y atención de las políticas públicas. Aun cuando un área pueda ser más apropiada para la explotación minera que para la agropecuaria (como el norte árido de Chile o las áreas rocosas del Perú), las inversiones del Estado en infraestructura en esas áreas desvían posibles recursos que podrían utilizarse para apoyar otras actividades en otras localidades o territorios (como la agropecuaria). También hay áreas que en un comienzo pueden utilizarse simultáneamente para la minería y para el desarrollo de actividades agropecuarias, pero es muy probable que con el tiempo una de dichas actividades termine expulsando a la otra. Según Lagos y Peters (2010, pág. 3) "En Argentina, por ejemplo, la minería era de importancia en las provincias cordilleranas de Mendoza, San Juan, La Rioja, Catamarca, Salta, Jujuy y Neuquén. Ya a fines del siglo XIX la minería perdió impulso frente a la importancia creciente de la agricultura y la ganadería. Recientemente, en la última década del siglo XX el establecimiento de una nueva estructura legal facilitó una importante inversión minera, dando lugar al surgimiento de minas como Bajo de la Alumbrera (cobre y oro), Cerro Vanguardia y Farallón Negro (oro y plata), Martha (plata), Salar del Hombre Muerto (litio), Andacollo y Veladero (oro), y San José (oro, plata y cobre). La tensión entre la agricultura y la minería no se ha reducido, sin embargo, y en provincias como Mendoza, por ejemplo, se elaboraron en la última década leyes especiales destinadas a dificultar la actividad minera". Los mismos autores (Lagos y Peters, 2010, pág. 5) citan el caso del área alrededor de Lima, donde la minería convivía con la producción campesina. Con el paso del tiempo, esta última fue desapareciendo y los campesinos se convirtieron en la mano de obra asalariada necesaria para sostener la expansión minera.

\section{Revisión de la literatura}

La literatura incluye una serie de estudios sobre la importancia de la actividad agropecuaria en el PIB de los países sudamericanos ${ }^{1}$. En algunos de los estudios se analizan países por separado, mientras en otros se analizan en conjunto. Asimismo, hay una extensa literatura sobre el papel de la producción de petróleo y productos mineros en el PIB de los países de América del Sur. Sin embargo, en ningún documento se ha abordado detenidamente el análisis conjunto de estos sectores en el PIB, ni hay un registro comparativo de estos sectores entre los países de la región.

En primer lugar, vista la diversidad de los territorios de América del Sur, en esta sección se separa a los países de la región en tres bloques: países de la Región Andina, las Guayanas ${ }^{2}$ y los países fundadores del MERCOSUR. Los países de la Región Andina son: Bolivia (Estado Plurinacional de), Chile, Colombia, Ecuador, Perú y Venezuela (República Bolivariana de). Estos son atravesados por la cordillera de los Andes, que les permite, desde la colonización española, tanto la explotación minera como la realización de actividades agropecuarias. Estas últimas se realizan sobre todo en las mesetas, las faldas y los pies de la cordillera y también en las llanuras. A partir de la década de 1990, la explotación minera y de hidrocarburos atrajo a nuevas empresas multinacionales, entre las que se destacan las chinas. Las Guayanas representan un área de meseta todavía poco explorada, en la que se distinguen dos países independientes: Guyana y Suriname. Por último, los países fundadores del MERCOSUR (Argentina, Brasil, Paraguay y Uruguay) comparten las planicies bañadas por el sistema de ríos que componen la Cuenca del Plata, en la que se desarrollan una extensa agricultura (principalmente de granos) y la ganadería. A nivel del MERCOSUR se destacan la Argentina y el Brasil, cuyos vastos territorios pueden utilizarse tanto para la producción agropecuaria como para la minería.

\footnotetext{
1 En este artículo se utiliza el término "agropecuaria" como la suma de la producción agrícola (agricultura) y pecuaria. En los artículos citados en este apartado muchas veces se utiliza el término "agricultura" como sinónimo de "agropecuaria".

2 A los efectos de este análisis las Guayanas comprenden dos países independientes, Guyana y Suriname, sin incluir la Guayana Francesa.
} 
Entre los países andinos, se destaca la República Bolivariana de Venezuela por su gran producción de petróleo, que constituye la actividad más importante en la economía venezolana desde la década de 1920. Al respecto, las exportaciones de petróleo de la República Bolivariana de Venezuela representaron el 40,7\% del PIB en 2006 y casi el 90\% de las exportaciones totales realizadas en el mismo año (Souza, 2008). Es importante resaltar que existen pocos estudios sobre el sector agropecuario de ese país. Uno de esos pocos es el trabajo de Morales (2002), quien realiza un análisis de las importaciones de maíz, trigo y leche en la República Bolivariana de Venezuela.

Uno de los países de América Latina en los que la participación del sector agropecuario en el PIB se redujo en las últimas décadas es Colombia. En ese país, la participación del sector agropecuario pasó del 20\% del PIB en 1970 al 7,7\% en 2010 (Fernández, Piñeros y Estrada, 2011; Romero, 2011). De acuerdo con Rudas y Espitia (2013), la explotación de minas e hidrocarburos representó alrededor del 7\% del PIB colombiano en 2012.

Al igual que en la República Bolivariana de Venezuela, la actividad petrolera también representa una considerable proporción de la economía en el Ecuador. Mateo y García (2014) muestran que el sector petrolero es el más destacado en la economía ecuatoriana, pues en 2012 representó más del 12\% del PIB y fue uno de los principales productos exportados (58\%). Por otra parte, la actividad agropecuaria tiene una relevancia mucho menor en la economía ecuatoriana. Según Tandazo (2012), la agropecuaria representaba cerca del 10\% del valor agregado bruto (VAB) ecuatoriano en ese año, incluida la pesca.

En el Perú, según la Organización de las Naciones Unidas para la Alimentación y la Agricultura (FAO, 2006), la agropecuaria tiene poca rentabilidad y baja competitividad. En ese país el énfasis de las actividades rurales es también la minería, puesto que el Perú es el principal productor mundial de plata, con una participación del 6,5\% de la producción mundial de ese mineral en 2006. Ese mismo año, el Perú fue también el tercer mayor productor mundial de cobre y zinc, el cuarto productor de plomo y el quinto de oro (Dammert y Molinelli, 2007). Landa (2017) evalúa el impacto de la producción de cobre en la infraestructura educativa, sanitaria y vial peruana entre 2004 y 2013 y muestra que dicha infraestructura ha mejorado más en las zonas de extracción que en las otras. No obstante, esa mejora es pequeña con respecto a su potencial.

En el caso del Estado Plurinacional de Bolivia, de acuerdo con Urioste (2009), la participación de la agropecuaria en el PIB fue del 13\% en 2008, la tasa más baja desde 1983. Montenegro y Guzmán (1999) muestran que el sector agropecuario representaba el 15\% del PIB boliviano en 1995 y 1997, el valor más bajo observado en las series de tiempo de 1970 a 1997. Por otra parte, las exportaciones de minerales representaron alrededor del $20 \%$ del total exportado por el Estado Plurinacional de Bolivia en el período de 2005 a 2008, superadas solamente por las exportaciones de gas natural, que - como señala Urioste (2009) - aumentaron significativamente a partir de 2003.

El principal producto exportado por la minería chilena es el cobre, cuyo valor en las exportaciones alcanzó casi 18.000 millones de dólares en 2004 (Guajardo, 2007). El sector agropecuario tiene un papel secundario en el PIB de Chile y, aunque se observa un aumento real constante en el valor de la producción desde 1962, este solo representaba el 3,09\% del PIB en 2007 (INE-Chile, 2009).

Guyana y Suriname están situados en el norte de América del Sur y se independizaron de Inglaterra y de los Países Bajos, respectivamente, recién en la década de 1970. Aunque sus economías están en estado embrionario y la infraestructura es muy deficiente, Guyana y Suriname tienen un gran potencial productivo en los sectores energético y minero (Visentini, 2010). La economía de Guyana sigue dependiendo de la exportación de pocos productos no procesados, como el oro y el arroz (Gold, Atoyan y Staritz, 2007). En Suriname, la actividad agropecuaria sigue siendo poco representativa, con una participación del 9\% del PIB en el período 1992-1995 (Boye y Ramautarsing, 1997). De acuerdo con Visentini (2010), en Suriname existe la posibilidad de una mayor exploración de yacimientos de oro y, por consiguiente, de una mayor producción de petróleo y gas. 
En la parte meridional de América del Sur se encuentran los países del Río de la Plata, a saber: Argentina, Paraguay y Uruguay. La cuenca del Río de la Plata es muy extensa y está formada por tres ríos (Paraná, Paraguay y Uruguay) que nacen en el Brasil. Con suelos muy fértiles, es una región con buenas condiciones para el desarrollo de actividades agropecuarias (Zarilli, 2013).

Con respecto a la importancia de la actividad agropecuaria en la economía argentina se puede, por ejemplo, citar la obra de Reca (2006), que analiza el desarrollo agrícola y ganadero de la Argentina desde 1875 hasta 2005. Según ese estudio, el sector agropecuario argentino creció en forma considerable durante el citado período y el país se convirtió en uno de los principales exportadores mundiales de granos, carne vacuna, lana y aceites vegetales. Sin embargo, se observan algunas fluctuaciones en los últimos años analizados. Si bien hubo una disminución del valor agregado de la agropecuaria desde 1999 hasta 2002 (debido a la crisis económica que enfrentó el país en esos años), entre 2003 y 2005 esa cifra registró una tasa de crecimiento promedio anual del 5\%, un nivel similar al alcanzado en el período 1875-1928, cuando en la economía argentina predominaba la ganadería. Ese país es uno de los principales productores de carne del mundo y su producción de carne de pollo y de cerdo ha aumentado más que la de carne de res (Reca y Lema, 2016). Según Lence (2010), casi la mitad de las exportaciones argentinas entre 2000 y 2007 fueron de productos agropecuarios, que representaron el 8,4\% de la producción agropecuaria mundial en ese período. Puyana y Constantino (2013) analizan esa expansión agrícola y la dependencia de la balanza comercial argentina de los productos agrícolas (en especial la soya), pero no encuentran indicios de la enfermedad holandesa en la Argentina.

En el Paraguay y el Uruguay la agropecuaria también constituye una parte importante del PIB y de la balanza comercial. Ese sector representó aproximadamente el $24 \%$ del PIB del Paraguay en el período 2000-2010 (Servín, 2011). En 2013 la agropecuaria fue responsable del 24,6\% del PIB paraguayo y representó en promedio el 27,8\% de las exportaciones de ese país entre 2000 y 2013 (Cresta y otros, 2014). En el Uruguay, los datos del INE-Uruguay (2009) indican que la actividad agropecuaria representaba el 9,9\% del PIB en 2010. Oyhantçabal y Sanguinetti (2017), que analizan los cambios en la actividad agropecuaria uruguaya entre 2000 y 2015, evalúan la distribución del ingreso y señalan que los terratenientes han captado una gran parte de ese ingreso.

El Brasil es el país sudamericano más grande en términos geográficos. En la actualidad, es uno de los más importantes productores y exportadores de productos agropecuarios del mundo. En un estudio relativo al período 1955-1996, Bacha y Rocha (1998) encontraron una disminución de la participación del sector agropecuario en el PIB brasileño, del 23,5\% en 1955 al 7,7\% en 1989. Sobre la base de otro conjunto de datos de la contabilidad nacional de Brasil, Bacha (2012) analizó el período 1947-2010 y observó un aumento de la contribución de la actividad agropecuaria al PIB brasileño entre 1998 y 2003. Este se debió a tres factores principales: i) el aumento de la productividad agropecuaria combinado con la disminución de la productividad en el sector industrial; ii) la mejora en la relación de los precios agrícolas en comparación con los industriales; iii) la mejora en la relación entre los precios cobrados y los pagados por la ganadería y la agricultura. Sin embargo, los años 2005 y 2006 se caracterizaron por la disminución de la importancia de la actividad agropecuaria en el PIB del Brasil (debido en gran parte a la fuerte apreciación del real ante el dólar y a la reducción de los precios internacionales de los productos agrícolas). Entre 2007 y 2010 se observa una recuperación de esa participación.

En la década de 1990, con el mayor grado de liberalización económica, el Brasil se consolidó como el principal productor y exportador de varios productos agropecuarios, como jugo de naranja, azúcar y carne de pollo, además de los productos de la cadena productiva de la soja (Jales, 2005). Bacha (2011) señala que, desde 1998, el aumento de la producción agropecuaria y el incremento de los precios de los productos básicos permitieron un gran crecimiento de la producción y las exportaciones agropecuarias brasileñas, que a su vez permitió la recuperación del PIB agropecuario de este país. La contribución del sector agropecuario al PIB brasileño también es analizada por 
Brugnaro y Bacha (2009). A partir de datos relativos al período 1986-2004, los autores encontraron que, a pesar de la tendencia histórica a la pérdida de importancia de la agropecuaria en el PIB brasileño, esa trayectoria se invirtió entre 1993 y 2004.

Por último, como se mencionó anteriormente, mientras algunos estudios en la literatura se concentran en América Latina, en otras obras se analizan algunos países de la región en forma individual. Al respecto, de acuerdo con Pardey, Wood y Hertford (2009), en América Latina existe una correlación positiva entre el crecimiento del PIB total y el PIB agropecuario en el período 1961-2002, sobre todo en países como Belice, el Brasil, México y el Paraguay. A pesar de eso, el período 1961-2002 se caracterizó por la disminución de la cuota de la actividad agropecuaria en el PIB total de los países latinoamericanos.

En términos de comercio, el superávit comercial de los productos agropecuarios en América Latina obedece al desempeño comercial de unos pocos países, especialmente la Argentina y el Brasil, donde se registraron los mayores superávits en 1999. Por el contrario, la República Bolivariana de Venezuela, Chile y Suriname, entre otros, presentan saldos negativos en la balanza comercial de los productos agropecuarios (Acosta, 2006). Valdés y Foster (2011) también señalan la importancia de la actividad agropecuaria en la balanza comercial de esos países en el período de 2000 a 2002. Según esos autores, entre los países analizados, solo la Argentina, el Uruguay, el Brasil, el Paraguay y el Estado Plurinacional de Bolivia fueron exportadores netos de alimentos, en especial los cuatro primeros.

En general, la literatura analizada ha perdido actualidad, pues en los últimos diez años se han producido muchos cambios en los países estudiados en las obras citadas. Por otra parte, no se encontró en la literatura un análisis para los países sudamericanos con respecto a la compensación en el uso de los factores de producción (en especial el uso de la tierra) entre la agropecuaria y la extracción minera y de hidrocarburos.

En la sección siguiente se destaca esta compensación. Para ello se analiza el período desde 1960 hasta 2014, abarcando así un período más largo con respecto a la bibliografía analizada.

\section{Resultados}

Este documento se basa en un conjunto de datos del Banco Mundial (s/f) y de la Organización de las Naciones Unidas para la Agricultura y la Alimentación (FAO). Ambos organismos suministran información similar sobre los países de América del Sur en materia de: i) uso de factores de producción (como tierra, capital y trabajo); ii) valor bruto y valor agregado de la producción agropecuaria, y iii) indicadores macroeconómicos, como la balanza comercial y la participación de la actividad agropecuaria y de la producción de hidrocarburos y minería en el PIB. Estos datos se organizaron en cuadros y gráficos. Algunas series de datos están disponibles desde 1960 y otras desde 1990. La disponibilidad de una serie de datos desde 1960 favorece la comparación entre los períodos anteriores y posteriores a la apertura económica implementada en los países sudamericanos en los años noventa.

\section{Disponibilidad de tierras, inversión en capital fijo y productividad del trabajo agrícola en los países de América del Sur}

En general, entre 1961 y 2013 el área de tierras cultivables con respecto al área total disponible se amplió en todos los países de América del Sur (véase el cuadro 1). Sin embargo, los tres grupos previamente mencionados (MERCOSUR, países andinos y las Guayanas) presentan diferentes patrones en relación con el uso del suelo. 


\section{Cuadro 1}

América del Sur (12 países): tierras agrícolas con respecto a la tierra total disponible, 1961-2013 (En porcentajes, valores anuales promedio, por quinquenio)

\begin{tabular}{lcccccc}
\hline \multirow{2}{*}{ País } & \multicolumn{7}{c}{ Años } \\
\cline { 2 - 7 } & $1961-1964$ & $1970-1974$ & $1980-1984$ & $1990-1994$ & $2000-2004$ & $2010-2013^{\text {a }}$ \\
\hline Argentina & 49,55 & 47,15 & 46,91 & 46,68 & 47,58 & 54,28 \\
\hline Brasil & 18,96 & 24,26 & 27,21 & 29,53 & 31,86 & 33,00 \\
\hline Paraguay & 26,65 & 29,37 & 35,13 & 42,83 & 49,88 & 53,93 \\
\hline Uruguay & 92,60 & 87,99 & 85,83 & 85,28 & 85,25 & 82,21 \\
\hline Bolivia (Estado Plurinacional de) & 27,62 & 28,70 & 31,51 & 33,17 & 34,13 & 34,54 \\
\hline Chile & 18,35 & 21,02 & 22,39 & 21,03 & 20,76 & 21,21 \\
\hline Colombia & 37,05 & 40,26 & 40,85 & 40,51 & 38,33 & 38,68 \\
\hline Ecuador & 17,03 & 18,02 & 24,96 & 28,77 & 30,70 & 30,06 \\
\hline Perú & 13,51 & 14,18 & 14,66 & 17,08 & 17,93 & 18,90 \\
\hline Venezuela (República Bolivariana de) & 21,92 & 22,78 & 24,01 & 24,61 & 24,48 & 24,49 \\
\hline Guyana & 6,91 & 6,98 & 8,74 & 8,81 & 8,68 & 8,52 \\
\hline Suriname & 0,27 & 0,34 & 0,47 & 0,57 & 0,52 & 0,50 \\
\hline
\end{tabular}

Fuente: Elaboración propia, sobre la base de datos del Banco Mundial, "World Development Indicators (WDI)" (s/f) [base de datos en línea] http://databank.worldbank.org/data/reports.aspx?source=world-development-indicators.

a Datos de 2014 no disponibles en la base de datos utilizada, promedio de cuatro años.

El Uruguay es el país sudamericano con la mayor proporción del total de tierras destinada a la actividad agropecuaria. En el período analizado, al menos el 82\% del territorio uruguayo se dedicó a uso agrícola. Por otra parte, en el Paraguay se observan fuertes cambios en el uso del suelo. Entre los períodos 1961-1964 y 2010-2013 se duplicó la proporción de tierras destinadas a la producción agropecuaria, que pasó de un promedio del 26,65\% a un promedio del 53,93\%. El Uruguay y el Paraguay, al igual que la Argentina y el Brasil, poseen condiciones climáticas y geográficas que favorecen el desarrollo de las actividades agropecuarias, en particular la producción de granos y la ganadería. Con respecto a estos dos últimos, se observa que mientras al menos la mitad del territorio de la Argentina está destinada a dicha actividad desde mediados de la década de 2000, estas actividades ocupan un tercio del territorio del Brasil.

Entre los países andinos, el Estado Plurinacional de Bolivia y Colombia dedican más del $30 \%$ de su territorio a la producción agropecuaria, mientras en Chile y el Perú esta proporción es inferior al 23\%. A pesar de que en Guyana y Suriname ha aumentado el área destinada a la actividad agropecuaria, esta no representa más del 9\% y el 1\% de sus territorios, respectivamente (véase el cuadro 1).

Los datos del cuadro 2 muestran que la mayoría de los países estudiados registraron un aumento en el capital empleado en la actividad agropecuaria entre 1990 y 2009, con excepción de la Argentina, el Ecuador, Guyana y Suriname. Esto puede indicar que en la mayoría de los países de América del Sur se ha invertido más capital en el sector agropecuario, muy seguramente acompañado de mejoras tecnológicas. 


\section{Cuadro 2}

América del Sur (12 países): valor del capital agrícola, 1990-2009

(En millones de dólares de 2005, valores promedio por quinquenio)

\begin{tabular}{|c|c|c|c|c|c|}
\hline \multirow[b]{2}{*}{ País } & \multicolumn{4}{|c|}{ Años } & \multirow{2}{*}{$\begin{array}{c}\text { Tasa de crecimiento } \\
\text { entre (D) y (A) } \\
\text { (en porcentajes) }\end{array}$} \\
\hline & $\begin{array}{c}1990-1994 \\
\text { (A) }\end{array}$ & $\begin{array}{l}1995-1999 \\
\text { (B) }\end{array}$ & $\begin{array}{c}2000-2004 \\
\text { (C) }\end{array}$ & $\begin{array}{l}2005-2009^{a} \\
\text { (D) }\end{array}$ & \\
\hline Argentina & 80542,25 & 76518,69 & 76 395,35 & 78691,86 & $-2,3$ \\
\hline Brasil & 178040,60 & 184457,10 & 200 059,20 & 212934,90 & 19,6 \\
\hline Paraguay & 6782,61 & 7665,08 & 7706,85 & 8259,37 & 21,8 \\
\hline Uruguay & 22890,60 & 23 290,34 & 23258,09 & 25045,91 & 9,4 \\
\hline Bolivia (Estado Plurinacional de) & 6470,62 & 7189,41 & 8157,64 & 9072,33 & 40,2 \\
\hline Chile & 20305,29 & 22 627,82 & 22 995,87 & 22872,66 & 12,6 \\
\hline Colombia & 97 536,07 & 100675,30 & 97900,85 & 101015,10 & 3,6 \\
\hline Ecuador & 20038,09 & 20977,49 & 19689,86 & 19279,80 & $-3,8$ \\
\hline Perú & 19824,48 & 21258,93 & 22601,76 & 23442,91 & 18,3 \\
\hline Venezuela (República Bolivariana de) & 26399,50 & 27168,88 & 28563,28 & 29442,64 & 11,5 \\
\hline Guyana & 1112,20 & 1078,95 & 1055,91 & 1045,46 & $-6,0$ \\
\hline Suriname & 727,40 & 744,65 & 751,94 & 689,29 & $-5,2$ \\
\hline
\end{tabular}

Fuente: Elaboración propia, sobre la base de datos de la Organización de las Naciones Unidas para la Alimentación y la Agricultura (FAO), "FAOSTAT" (s/f) [base de datos en línea] http://faostat3.fao.org.

Nota: En este cálculo no se tienen en cuenta la silvicultura y la pesca. Los activos físicos considerados para este cálculo incluyen los utilizados en los procesos de producción que cubren el uso del suelo, obras de riego, estructuras, maquinaria y animales.

a Datos de 2008 y 2009 no disponibles en FAOSTAT, valor promedio de tres años.

Si bien la actividad agropecuaria es prominente en la Argentina, este sector ha perdido importancia en el PIB del país en las últimas décadas. El valor agregado de esa actividad aumentó aún más en el período posterior a 2003, como señala Reca (2006). Por lo tanto, la disminución del valor de las existencias de capital fijo en la actividad agropecuaria argentina en la década de 1990 y su aumento en la década siguiente pueden estar relacionados con el desempeño de la economía argentina en décadas pasadas. Al contrario del caso argentino, se observa que el Ecuador, Guyana y Suriname no tienen una fuerte inclinación a dicha actividad. En estos tres países se ha registrado un creciente uso del suelo en actividades diferentes a la agropecuaria, tendencia que a su vez está relacionada con una reducción en las existencias de capital fijo en ese sector.

A pesar de la evolución heterogénea de la formación bruta de capital fijo, el valor agregado bruto agropecuario por trabajador (un indicador de la productividad agrícola, véase el cuadro 3) aumentó significativamente a lo largo del tiempo en todos los países sudamericanos. En promedio, se registró un crecimiento mayor en los países fundadores del MERCOSUR que en el resto de los países estudiados. Dos factores clave en la explicación de estas diferencias son el aumento mundial de los precios de los productos agrícolas y el mayor empleo de mano de obra calificada en la agropecuaria, especialmente en las décadas de 2000 y 2010. 


\section{Cuadro 3}

América del Sur (11 países): valor agregado bruto del sector agropecuario por trabajador, 1990-2014

(En dólares de 2005, valores promedio por quinquenio)

\begin{tabular}{|c|c|c|c|c|c|c|}
\hline \multirow[b]{2}{*}{ País } & \multicolumn{5}{|c|}{ Años } & \multirow{2}{*}{$\begin{array}{c}\text { Tasa de crecimiento } \\
\text { entre }(\mathrm{E}) \text { y }(\mathrm{A}) \\
\text { (en porcentajes) }\end{array}$} \\
\hline & $\begin{array}{l}1990-1994 \\
\text { (A) }\end{array}$ & $\begin{array}{l}1995-1999 \\
\text { (B) }\end{array}$ & $\begin{array}{l}2000-2004 \\
\text { (C) }\end{array}$ & $\begin{array}{l}2005-2009 \\
\text { (D) }\end{array}$ & $\begin{array}{l}2010-2014 \\
\text { (E) }\end{array}$ & \\
\hline Argentina & 7670,36 & 9203,27 & 9918,16 & 11638,02 & 12293,46 & 60,3 \\
\hline Brasil & 1741,92 & 2157,83 & 2859,53 & 3753,83 & 4959,65 & 184,7 \\
\hline Paraguay & $1678,44^{a}$ & 1846,01 & 1910,79 & 2207,43 & 2807,21 & 67,3 \\
\hline Uruguay & 5852,37 & 7310,11 & 7201,98 & 8215,57 & 9410,55 & 60,8 \\
\hline Bolivia (Estado Plurinacional de) & 621,96 & 629,69 & 617,01 & 639,41 & 643,99 & 3,5 \\
\hline Chile & 3303,21 & 3615,41 & 4717,61 & 5697,36 & 6371,00 & 92,9 \\
\hline Colombia & 3509,61 & 2959,87 & 2889,40 & 3308,13 & 3657,16 & 4,2 \\
\hline Ecuador & 2086,87 & 2405,62 & 2792,12 & 3398,61 & 4000,32 & 91,7 \\
\hline Perú & 1029,24 & 1230,21 & 1401,20 & 1625,90 & $1848,03^{b}$ & 79,6 \\
\hline Guyana & 3248,93 & 4473,55 & 4781,87 & 4291,03 & $4761,84^{b}$ & 46,6 \\
\hline Suriname & 3 172,20 & 2753,69 & 2955,24 & 3 009,33 & $3848,04^{c}$ & 21,3 \\
\hline
\end{tabular}

Fuente: Elaboración propia, sobre la base de datos del Banco Mundial, "World Development Indicators (WDI)" (s/f) [base de datos en línea] http://databank.worldbank.org/data/reports.aspx?source=world-development-indicators.

a Datos de 1990 no disponibles en la base de datos utilizada, promedio de cuatro años.

b Datos de 2013 y 2014 no disponibles en la base de datos utilizada, promedio de tres años.

c Datos de 2014 no disponibles en la base de datos utilizada, promedio en cuatro años.

\section{Producción y balanza comercial agropecuaria en los países de América del Sur}

Entre 1990 y 2013, los valores de la producción agrícola y pecuaria aumentaron en todos los países sudamericanos examinados, con excepción de Suriname (véase el cuadro 4). En el caso de la producción agrícola, el aumento fue mayor en los países fundadores del MERCOSUR que en los países andinos, mientras en el caso de la producción pecuaria el proceso fue inverso. El crecimiento en los valores de producción, tanto agrícola como pecuaria, es resultado de la expansión de las tierras cultivables, del capital fijo y de una productividad laboral creciente, como se indica en los cuadros 1 a 3, respectivamente. La mayor abundancia de llanuras en los países del MERCOSUR en relación con los países andinos significó una ventaja comparativa para que los primeros aumentaran con más rapidez la producción de granos. En algunos países andinos, muchas de las zonas rocosas resultan más favorables para la ganadería que para cultivos agrícolas. 


\section{Cuadro 4}

América del Sur (11 países): valor promedio anual de la producción agrícola y pecuaria, 1990-2014

(En millones de dólares promedio de 2004 a 2006, valores promedio anuales por quinquenio)

\begin{tabular}{|c|c|c|c|c|c|c|}
\hline \multirow[b]{2}{*}{ País } & \multicolumn{5}{|c|}{ Años } & \multirow{2}{*}{$\begin{array}{c}\text { Tasa de crecimiento } \\
\text { entre (E) y (A) } \\
\text { (en porcentajes) }\end{array}$} \\
\hline & $\begin{array}{l}\text { 1990-1994 } \\
\text { (A) }\end{array}$ & $\begin{array}{l}1995-1999 \\
\text { (B) }\end{array}$ & $\begin{array}{c}2000-2004 \\
\text { (C) }\end{array}$ & $\begin{array}{l}2005-2009 \\
\text { (D) }\end{array}$ & $\begin{array}{l}2010-2013^{a} \\
(E)\end{array}$ & \\
\hline \multicolumn{7}{|l|}{ Producción agrícola } \\
\hline Argentina & 8874,81 & 11373,72 & 13651,46 & 16209,11 & 18539,29 & 108,9 \\
\hline Brasil & 25035,17 & 28377,74 & 35894,12 & 44052,61 & 52712,74 & 110,6 \\
\hline Paraguay & 722,51 & 979,77 & 1258,33 & 1678,40 & 2383,56 & 229,9 \\
\hline Uruguay & 495,03 & 672,16 & 655,72 & 955,22 & 1395,96 & 182,0 \\
\hline Bolivia (Estado Plurinacional de) & 622,71 & 810,15 & 970,40 & 1097,04 & 1308,49 & 110,1 \\
\hline Chile & 2196,95 & 2480,69 & 2766,46 & 2835,81 & 3070,25 & 39,8 \\
\hline Colombia & 5501,58 & 5366,71 & 5570,88 & 6048,33 & 5933,28 & 7,8 \\
\hline Ecuador & 1583,48 & 1808,60 & 1835,06 & 1959,33 & 2219,07 & 40,1 \\
\hline Perú & 1373,71 & 2040,93 & 2648,63 & 3165,37 & 3826,75 & 178,6 \\
\hline Guyana & 3,91 & 6,47 & 5,85 & 7,57 & 6,54 & 67,3 \\
\hline Suriname & 96,97 & 84,71 & 71,71 & 79,39 & 94,08 & $-3,0$ \\
\hline \multicolumn{7}{|l|}{ Producción pecuaria } \\
\hline Argentina & 1973,98 & 2652,88 & 2593,54 & 3257,18 & 3808,27 & 92,9 \\
\hline Brasil & 14500,07 & 19312,28 & 24662,94 & 30528,29 & 34738,48 & 139,6 \\
\hline Paraguay & 550,54 & 634,27 & 742,11 & 853,53 & 980,12 & 78,0 \\
\hline Uruguay & 1105,10 & 1304,70 & 1202,65 & 1488,01 & 1519,57 & 37,5 \\
\hline Bolivia (Estado Plurinacional de) & 281,28 & 334,53 & 376,09 & 512,23 & 575,43 & 104,6 \\
\hline Chile & 1437,30 & 1842,72 & 2100,24 & 2603,46 & 2816,52 & 96,0 \\
\hline Colombia & 3427,38 & 4002,99 & 4466,68 & 5461,96 & 5926,12 & 72,9 \\
\hline Ecuador & 1077,27 & 1542,32 & 1843,95 & 2183,43 & 2589,97 & 140,4 \\
\hline Perú & 1173,61 & 1483,15 & 1859,20 & 2478,74 & 3194,89 & 172,2 \\
\hline Guyana & 7,89 & 11,67 & 14,03 & 19,60 & 18,93 & 139,9 \\
\hline Suriname & 45,61 & 31,65 & 29,62 & 34,76 & 40,78 & $-10,6$ \\
\hline
\end{tabular}

Fuente: Elaboración propia, sobre la base de datos de la Organización de las Naciones Unidas para la Alimentación y la Agricultura (FAO), "FAOSTAT" (s/f) [base de datos en línea] http://faostat3.fao.org.

Nota: Estos valores se calculan de acuerdo con la FAO, multiplicando la cantidad física de la producción bruta por los precios a puerta de granja.

a Datos de 2014 no disponibles en FAOSTAT, promedio de cuatro años.

Es bien sabido que el Brasil y la Argentina son, en ese orden, los mayores productores agrícolas y pecuarios de América del Sur, debido al tamaño de sus territorios y a su diversidad climática. No obstante, también es menester destacar el gran aumento en la producción agrícola del Uruguay y el Paraguay y de la producción pecuaria del Ecuador, el Estado Plurinacional de Bolivia, el Perú y Guyana. Gran parte de la producción agropecuaria de los países sudamericanos se destina a los mercados extranjeros. Todos los países sudamericanos examinados, excepto el Perú y Suriname, registran un superávit en el comercio de productos agropecuarios y agroindustriales (véase el cuadro 5). 


\section{Cuadro 5}

América del Sur (12 países): saldo de la balanza comercial de productos agropecuarios y agroindustriales, 1990-2014

(En millones de dólares, valores promedio por quinquenio)

\begin{tabular}{lrrrrc}
\hline \multirow{2}{*}{ País } & \multicolumn{4}{c}{ Años } & \\
\cline { 2 - 5 } & $1990-1994$ & $1995-1999$ & $2000-2004$ & $2005-2009$ & $2010-2013^{\text {a }}$ \\
\hline Argentina & 6363,68 & 9652,60 & 11552,21 & 23730,49 & 37329,78 \\
\hline Brasil & 6575,05 & 8749,22 & 15146,18 & 38089,01 & 66825,63 \\
\hline Paraguay & 413,94 & 181,39 & 572,85 & 1794,50 & 3789,57 \\
\hline Uruguay & 515,90 & 751,19 & 784,64 & 2163,76 & 4160,88 \\
\hline Bolivia (Estado Plurinacional de) & 49,10 & 180,44 & 233,04 & 427,60 & 869,54 \\
\hline Chile & 883,35 & 1355,97 & 2112,28 & 3287,58 & 5037,82 \\
\hline Colombia & 1999,20 & 1903,14 & 1305,79 & 2465,39 & 1206,92 \\
\hline Ecuador & 797,19 & 1178,10 & 1144,55 & 1799,00 & 2777,61 \\
\hline Perú & $-491,55$ & $-642,97$ & $-271,63$ & $-153,53$ & 79,79 \\
\hline Venezuela (República Bolivariana de) & $-810,06$ & $-1126,56$ & $-1701,49$ & $-5378,88$ & $-8617,49$ \\
\hline Guyana & 108,75 & 156,83 & 88,40 & 122,77 & 129,62 \\
\hline Suriname & $-20,44$ & $-58,85$ & $-68,01$ & $-125,70$ & $-148,54$ \\
\hline
\end{tabular}

Fuente: Elaboración propia, sobre la base de datos de la Organización de las Naciones Unidas para la Alimentación y la Agricultura (FAO), "FAOSTAT" (s/f) [base de datos en línea] http://faostat3.fao.org.

a Promedio de cuatro años.

Los países fundadores del MERCOSUR presentan el mejor desempeño en la balanza comercial. En este conjunto de países se incrementaron considerablemente tanto la producción como las exportaciones de productos agropecuarios y agroindustriales. En el Brasil, por ejemplo, el promedio de la producción agropecuaria anual creció un 110,6\% desde el período 1990-1994 al período 2010-2013. Al mismo tiempo, el valor promedio de la producción pecuaria anual del gigante sudamericano aumentó un 139,6\%. En consecuencia, el superávit de la balanza comercial del Brasil en estos productos creció un 916,4\% durante el mismo período. El Paraguay, el Uruguay y la Argentina también registraron un crecimiento importante, con un incremento del superávit comercial de los productos agropecuarios y agroindustriales del $815,5 \%$, el $706,5 \%$ y el $486,6 \%$, respectivamente. Queda claro que esas cifras los posicionan como países agroexportadores.

Acosta (2006) señala que la República Bolivariana de Venezuela y Suriname presentan déficits en la balanza comercial de productos agropecuarios y agroindustriales desde 1990, una tendencia que se mantiene en la década de 2000 (véase el cuadro 5). El Perú comparte con estos dos países el mal desempeño de la balanza comercial agropecuaria y agroindustrial.

El examen general de los cuadros 5 y 6 indica que los países con mayor producción agropecuaria son también aquellos que presentan los mayores superávits en las balanzas comerciales de productos agropecuarios y agroindustriales. 


\section{Cuadro 6}

América del Sur (12 países): participación del sector agropecuario y del sector de minería e hidrocarburos en el producto interno bruto (PIB) y valor agregado bruto (VAB) del sector agropecuario, 1990-2014

(En porcentajes y millones de dólares de 2004, promedio anual por quinquenios)

\begin{tabular}{|c|c|c|c|c|c|c|}
\hline \multirow{2}{*}{ País } & \multirow{2}{*}{ Indicador } & \multicolumn{5}{|c|}{ Años } \\
\hline & & $1990-1994$ & 1995-1999 & $2000-2004$ & $2005-2009$ & 2010-2014 \\
\hline \multirow[t]{3}{*}{ Argentina } & Participación del sector agropecuario en el PIB & 6,37 & 5,61 & 8,16 & 7,68 & 7,59 \\
\hline & VAB agropecuario & 11254,63 & 13577,04 & 14543,08 & 16787,16 & 17174,24 \\
\hline & $\begin{array}{l}\text { Participación del sector de minería } \\
\text { e hidrocarburos en el PIB }\end{array}$ & 1,50 & 1,40 & 3,84 & 3,79 & 3,43 \\
\hline \multirow{3}{*}{$\begin{array}{l}\text { Bolivia (Estado } \\
\text { Plurinacional de) }\end{array}$} & Participación del sector agropecuario en el PIB & 16,66 & 16,06 & 15,18 & 13,69 & $12,91^{\mathrm{a}}$ \\
\hline & VAB agropecuario & 765,24 & 894,69 & 1010,77 & 1181,96 & $1298,41^{\mathrm{a}}$ \\
\hline & $\begin{array}{l}\text { Participación del sector de minería } \\
\text { e hidrocarburos en el PIB }\end{array}$ & 3,12 & 2,20 & 3,97 & 8,50 & 9,24 \\
\hline \multirow[t]{3}{*}{ Brasil } & Participación del sector agropecuario en el PIB & 8,20 & 5,45 & 6,29 & 5,29 & 5,29 \\
\hline & VAB agropecuario & 24596,07 & 29563,82 & 37251,28 & 44503,25 & 51646,47 \\
\hline & $\begin{array}{l}\text { Participación del sector de minería } \\
\text { e hidrocarburos en el PIB }\end{array}$ & 1,35 & 0,95 & 2,91 & 4,22 & 4,78 \\
\hline \multirow[t]{3}{*}{ Chile } & Participación del sector agropecuario en el PIB & 9,45 & 6,71 & 5,31 & 3,87 & 3,37 \\
\hline & VAB agropecuario & 3155,41 & 3513,86 & 4560,25 & 5543,57 & 6094,67 \\
\hline & $\begin{array}{l}\text { Participación del sector de minería } \\
\text { e hidrocarburos en el PIB }\end{array}$ & 7,46 & 5,90 & 7,31 & 14,98 & 16,58 \\
\hline \multirow[t]{3}{*}{ Colombia } & Participación del sector agropecuario en el PIB & 15,98 & 14,21 & 8,96 & 7,87 & 6,77 \\
\hline & VAB agropecuario & 12063,42 & 10317,34 & 10351,11 & 11776,02 & 12720,00 \\
\hline & $\begin{array}{l}\text { Participación del sector de minería } \\
\text { e hidrocarburos en el PIB }\end{array}$ & 5,00 & 3,48 & 5,17 & 5,75 & 8,49 \\
\hline \multirow[t]{3}{*}{ Ecuador } & Participación del sector agropecuario en el PIB & 22,02 & 20,32 & 12,87 & 9,91 & 9,60 \\
\hline & VAB agropecuario & 3911,27 & 4918,57 & 3237,96 & 4969,26 & 7885,81 \\
\hline & $\begin{array}{l}\text { Participación del sector de minería } \\
\text { e hidrocarburos en el PIB }\end{array}$ & 9,62 & 7,51 & 13,36 & 16,99 & $17,48^{\mathrm{a}}$ \\
\hline \multirow[t]{3}{*}{ Guyana } & Participación del sector agropecuario en el PIB & 38,07 & 36,96 & 30,99 & 24,57 & 18,56 \\
\hline & VAB agropecuario & 185,69 & 249,53 & 260,05 & 223,16 & $234,45^{a}$ \\
\hline & $\begin{array}{l}\text { Participación del sector de minería } \\
\text { e hidrocarburos en el PIB }\end{array}$ & 8,82 & 4,57 & 3,35 & 5,36 & $12,94^{\mathrm{a}}$ \\
\hline \multirow[t]{3}{*}{ Paraguay } & Participación del sector agropecuario en el PIB & $17,57^{\mathrm{a}}$ & 18,18 & 16,83 & 20,47 & $26,34^{\mathrm{a}}$ \\
\hline & VAB agropecuario & $1028,04^{a}$ & 1250,36 & 1415,09 & 1763,59 & 2385,50 \\
\hline & $\begin{array}{l}\text { Participación del sector de minería } \\
\text { e hidrocarburos en el PIB }\end{array}$ & 0,00 & 0,00 & 0,00 & 0,00 & $0,00^{\mathrm{a}}$ \\
\hline \multirow[t]{3}{*}{ Perú } & Participación del sector agropecuario en el PIB & $9,30^{\mathrm{a}}$ & 9,38 & 8,39 & 7,62 & $7,39^{b}$ \\
\hline & VAB agropecuario & 2980,95 & 3917,06 & 4818,63 & 5877,49 & $6966,64^{a}$ \\
\hline & $\begin{array}{l}\text { Participación del sector de minería } \\
\text { e hidrocarburos en el PIB }\end{array}$ & 3,74 & 1,57 & 2,03 & 9,41 & $10,91^{a}$ \\
\hline \multirow[t]{3}{*}{ Suriname } & Participación del sector agropecuario en el PIB & 13,01 & 12,65 & 8,63 & 8,12 & $7,43^{\mathrm{a}}$ \\
\hline & VAB agropecuario & 91,37 & 79,28 & 89,85 & 97,00 & $126,99^{a}$ \\
\hline & $\begin{array}{l}\text { Participación del sector de minería } \\
\text { e hidrocarburos en el PIB }\end{array}$ & 20,01 & 8,07 & 11,00 & 12,68 & $25,93^{\mathrm{a}}$ \\
\hline \multirow[t]{3}{*}{ Uruguay } & Participación del sector agropecuario en el PIB & 8,36 & 7,82 & 9,24 & 10,34 & $9,49^{c}$ \\
\hline & VAB agropecuario & 1105,86 & 1408,38 & 1361,97 & 1562,28 & 1771,87 \\
\hline & $\begin{array}{l}\text { Participación del sector de minería } \\
\text { e hidrocarburos en el PIB }\end{array}$ & 0,00 & 0,00 & 0,03 & 0,10 & $0,12^{\mathrm{a}}$ \\
\hline \multirow{3}{*}{$\begin{array}{l}\text { Venezuela } \\
\text { (República } \\
\text { Bolivariana de) }\end{array}$} & Participación del sector agropecuario en el PIB & 5,44 & 5,02 & 4,29 & 4,54 & $5,56^{b}$ \\
\hline & VAB agropecuario & 4105,58 & 4267,59 & 4764,72 & 5595,08 & $5875,18^{a}$ \\
\hline & $\begin{array}{l}\text { Participación del sector de minería } \\
\text { e hidrocarburos en el PIB }\end{array}$ & 25,79 & 20,24 & 24,96 & 23,12 & $24,94^{a}$ \\
\hline
\end{tabular}

Fuente: Elaboración propia, sobre la base de datos del Banco Mundial, "World Development Indicators (WDI)" (s/f) [base de datos en línea] http://databank.worldbank.org/data/reports.aspx?source=world-development-indicators.

a Datos de uno de los años no disponibles en la base de datos utilizada, promedio de cuatro años.

b Datos de 2013 y 2014 no disponibles en la base de datos utilizada, promedio de tres años.

c Datos de 2012, 2013 y 2014 no disponibles en la base de datos utilizada, promedio de dos años. 


\section{Participación de la producción agropecuaria y de la explotación minera y de hidrocarburos en el PIB de los países sudamericanos}

En el cuadro 6 se muestra la evolución de la participación del sector agropecuario y del sector minero y de hidrocarburos (estos dos últimos tomados conjuntamente) en el PIB de los países sudamericanos de 1990 a 2014. Esta participación se calcula como el promedio anual por quinquenios y el valor agregado bruto del sector agropecuario se mide en millones de dólares a precios constantes de 2004 .

Los datos sugieren que, durante el período de análisis, la importancia de la explotación minera y de hidrocarburos aumentó en todos los países sudamericanos examinados, excepto el Paraguay y la República Bolivariana de Venezuela. En el caso del Paraguay, los datos indican que estos sectores no tienen participación en el PIB. En el caso de la República Bolivariana de Venezuela, visto que la explotación minera y de hidrocarburos ha tenido una gran importancia desde el inicio de la serie de datos (especialmente por la producción de petróleo), la escasa variación de su representatividad porcentual en el PIB entre 1990 y 2014 refleja la rigidez del aparato productivo de este país y su gran dependencia histórica del petróleo. En Chile, el Ecuador, Guyana, el Perú y Suriname, la participación de la minería y los hidrocarburos en el PIB también se ha incrementado. En forma análoga, y a pesar del predominio del sector agropecuario, la participación de la minería y los hidrocarburos en el PIB de la Argentina y el Brasil también ha aumentado a lo largo de la serie.

Al examinar el conjunto de datos del cuadro 6, se concluye que, en general, la importancia de la explotación minera y de hidrocarburos en las economías sudamericanas ha aumentado en los últimos años, acompañada al mismo tiempo por una marcada disminución del sector agropecuario como porcentaje del PIB en la mayoría de los países. Este patrón era esperado pues, desde mediados del siglo XX, la participación de los sectores industrial y de servicios en el valor agregado de la economía ha crecido más rápido que la del sector agropecuario.

A pesar de la tendencia a la baja de la importancia de la actividad agropecuaria en el PIB de los países de América del Sur, el valor agregado bruto de este sector se mantuvo al alza en la mayoría de esos países. En el Perú, por ejemplo, el VAB promedio de la agropecuaria aumentó un 133,71\% entre los quinquenios 1990-1994 y 2010-2014. Ese incremento fue del $110 \%$ en el Brasil, del 101,62\% en el Ecuador y del 93,15\% en Chile, por citar solo algunos países.

La Argentina, el Paraguay, el Uruguay y la República Bolivariana de Venezuela constituyen excepciones a la continua tendencia a la baja del sector agropecuario en el PIB a lo largo del tiempo. En estos países, aunque la participación del sector agropecuario en el PIB disminuyó entre 1990 y 1999, esa tendencia se invirtió en la década de 2000. Probablemente, el auge de los precios de los productos básicos agrícolas en el período 2002-2007 sea responsable, en parte, de esa inversión de tendencia. Sin embargo, y al igual que en el caso de la República Bolivariana de Venezuela con el petróleo, este escenario puede indicar la gran dependencia de las exportaciones agropecuarias en esos países (excepto la República Bolivariana de Venezuela).

La información proporcionada por la serie permite clasificar a los países en tres grupos diferentes, el primero de los cuales está conformado por la Argentina, el Brasil, el Paraguay y el Uruguay. Estos países, con excepción del Brasil, muestran un aumento de la participación de la actividad agropecuaria en el PIB al comparar el quinquenio 1990-1994 con el quinquenio 2010-2014. No obstante, el Brasil presenta el mayor valor agregado bruto de la agropecuaria de todos los países analizados. El segundo grupo está conformado por el Estado Plurinacional de Bolivia, Chile, Colombia, el Ecuador, el Perú y la República Bolivariana de Venezuela. En este grupo se observa una disminución del aporte porcentual de la actividad agropecuaria al PIB en la década de 2000. Aun así, con excepción de la República Bolivariana de Venezuela, en estos países también se registró 
un aumento del valor agregado del sector. En el caso venezolano, si bien la importancia del sector agropecuario como porcentaje del PIB se redujo entre 1990 y 2009, esta aumentó ligeramente a partir de 2010. El tercer grupo está compuesto por las Guayanas, donde en la década de 2000 -como se verá más adelante - el comportamiento de la participación agropecuaria en el PIB a lo largo de la serie muestra una forma de $U$ invertida y la participación de la minería y los hidrocarburos en el PIB se incrementó. Estos tres grupos de países se analizan en detalle a continuación.

\section{a) Argentina, Brasil, Paraguay y Uruguay}

En el caso de la Argentina, la relevancia del sector agropecuario como porcentaje del PIB creció considerablemente a partir de 2000 (véase el gráfico 1). Una parte de esa expansión se debe a la crisis económica que enfrentó el país a principios del siglo XXI (Reca, 2006). La agropecuaria argentina se apoyó principalmente en las exportaciones y, debido a esta característica, resultó poco afectada por la crisis económica interna, excepto durante los últimos años del segundo gobierno de Cristina Kirchner, quien buscaba la prohibición de las exportaciones agrícolas.

\section{Gráfico 1}

Argentina: participación de los sectores agropecuario y minero y petrolero en el producto interno bruto (PIB) y valor agregado del sector agropecuario, 1960-2014

(En porcentajes y millones de dólares de 2005)

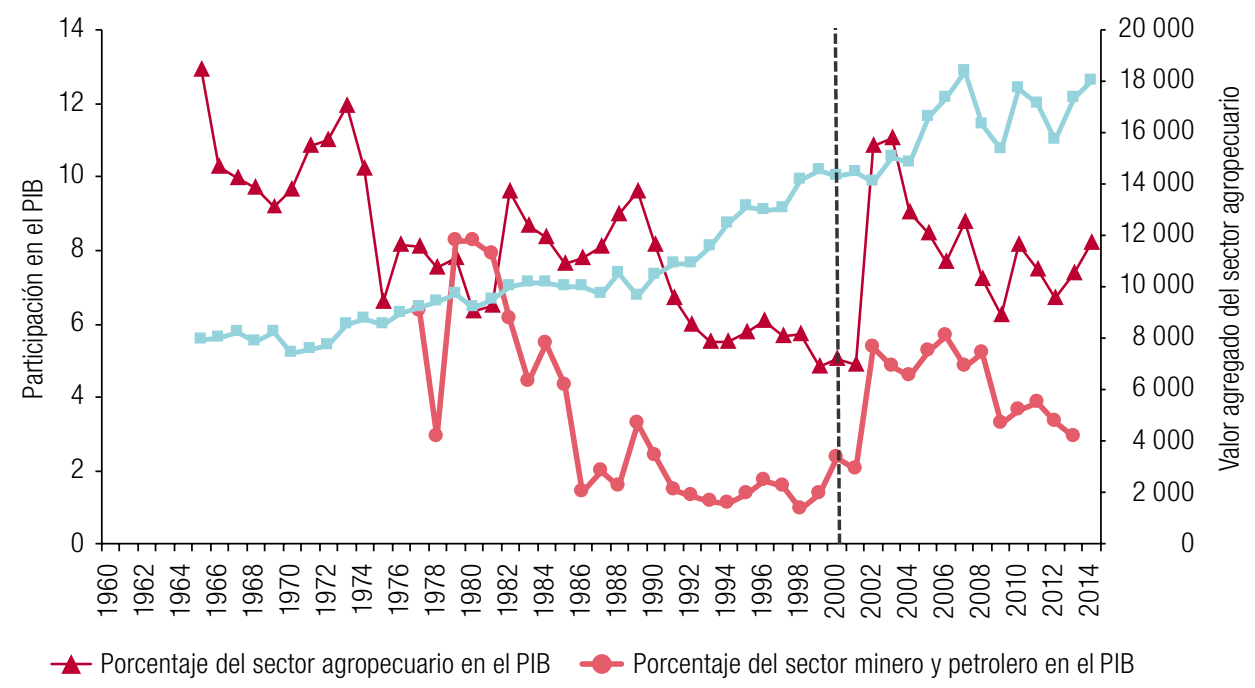

- PIB del sector agropecuario

Fuente: Elaboración propia, sobre la base de datos del Banco Mundial, "World Development Indicators (WDI)" (s/f) [base de datos en línea] http://databank.worldbank.org/data/reports.aspx?source=world-development-indicators.

Lo que más llama la atención en el gráfico 1 es la tendencia al alza del PIB a costo de factores (o VAB) agrícola argentino. A precios de 2005, el valor monetario aumentó de alrededor de 14.000 millones de dólares en 2010 a cerca de 18.000 millones de dólares en 2014. Además, desde los años noventa, el sector agrícola argentino se ha modernizado considerablemente, generando economías de escala derivadas de la apertura económica y de las ventajas comparativas de su agropecuaria (Lema, 1999). Cabe señalar que, a pesar de que la cuota de la producción minera y de hidrocarburos (tomadas conjuntamente) en el PIB argentino ha aumentado en el siglo XXI, continúa siendo inferior con respecto a la del sector agropecuario.

En el gráfico 2 se muestra el significativo aumento en el VAB agrícola del Brasil desde la década de 1960. Ese crecimiento se debió principalmente a las mejoras en la productividad con respecto a 
la disponibilidad de tierras y al crecimiento del área destinada a la producción agrícola, sobre todo en regiones como el centro-oeste y el norte del Brasil y, recientemente, en la región conocida como MATOPIBA, formada por los estados de Maranhão, Tocantins, Piauí y Bahia (Bacha y Carvalho, 2014). Sin embargo, la participación de la actividad agropecuaria en el PIB brasileño disminuyó de alrededor del 20\% en 1960 al 5\% en 2014. En el período de auge de los precios de productos básicos, ese valor superó el $7 \%$ (como en 2003). Después de la crisis de los precios (causada por la apreciación de la moneda brasileña, sobre todo en los años 2005 y 2006), entre 2007 y 2014, la participación de la agropecuaria en el PIB del Brasil ha oscilado entre el $5 \%$ y el $6 \%$.

\section{Gráfico 2}

Brasil: participación de los sectores agropecuario y minero y petrolero en el producto interno bruto (PIB) y valor agregado del sector agropecuario, 1960-2014

(En porcentajes y millones de dólares de 2005)

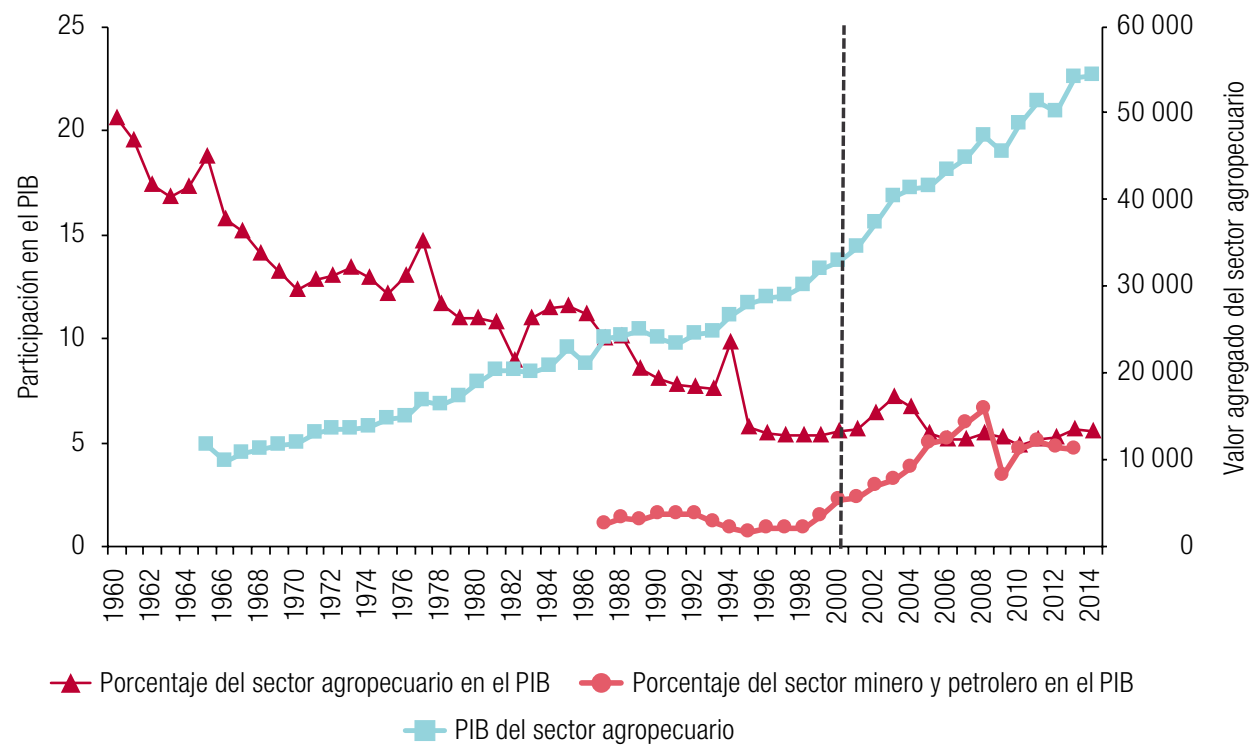

Fuente: Elaboración propia, sobre la base de datos del Banco Mundial, "World Development Indicators (WDI)" (s/f) [base de datos en línea] http://databank.worldbank.org/data/reports.aspx?source=world-development-indicators.

De acuerdo con los gráficos 1 y 2, tanto en la Argentina como en el Brasil hubo un incremento del porcentaje del PIB representado por las rentas procedentes de la minería y los hidrocarburos en los primeros 14 años del siglo XXI. Se sabe que en estas dos naciones hay una gran diversidad en cuanto a la formación geológica del suelo y el clima, que permite una producción agrícola a gran escala y la existencia de ventajas comparativas, tanto en la actividad agropecuaria como en la producción minera y de hidrocarburos.

Aunque el Paraguay y el Uruguay no tienen grandes extensiones de tierras, ambos dedican gran parte de su territorio a la actividad agropecuaria (véase el cuadro 1). El porcentaje de la renta minera y de hidrocarburos en la composición del PIB es prácticamente nulo, tanto en el Paraguay como en el Uruguay (véanse los gráficos 3 y 4). 


\section{Gráfico 3}

Paraguay: participación de los sectores agropecuario y minero y petrolero en el producto interno bruto (PIB) y valor agregado del sector agropecuario, 1960-2014

(En porcentajes y millones de dólares de 2005)

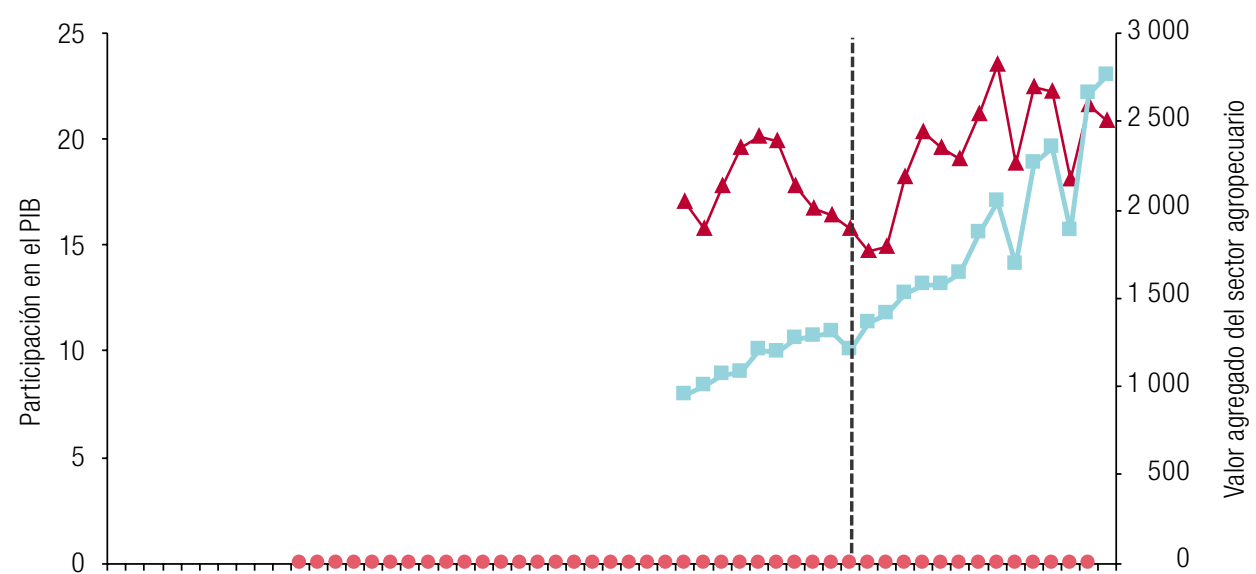

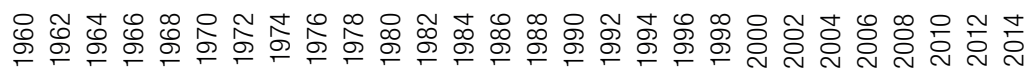

- - Porcentaje del sector agropecuario en el PIB $\quad$ - Porcentaje del sector minero y petrolero en el PIB

\section{- PIB del sector agropecuario}

Fuente: Elaboración propia, sobre la base de datos del Banco Mundial, "World Development Indicators (WDI)" (s/f) [base de datos en línea] http://databank.worldbank.org/data/reports.aspx?source=world-development-indicators.

\section{Gráfico 4}

Uruguay: participación de los sectores agropecuario y minero y petrolero en el producto interno bruto (PIB) y valor agregado del sector agropecuario, 1960-2014

(En porcentajes y millones de dólares de 2005)

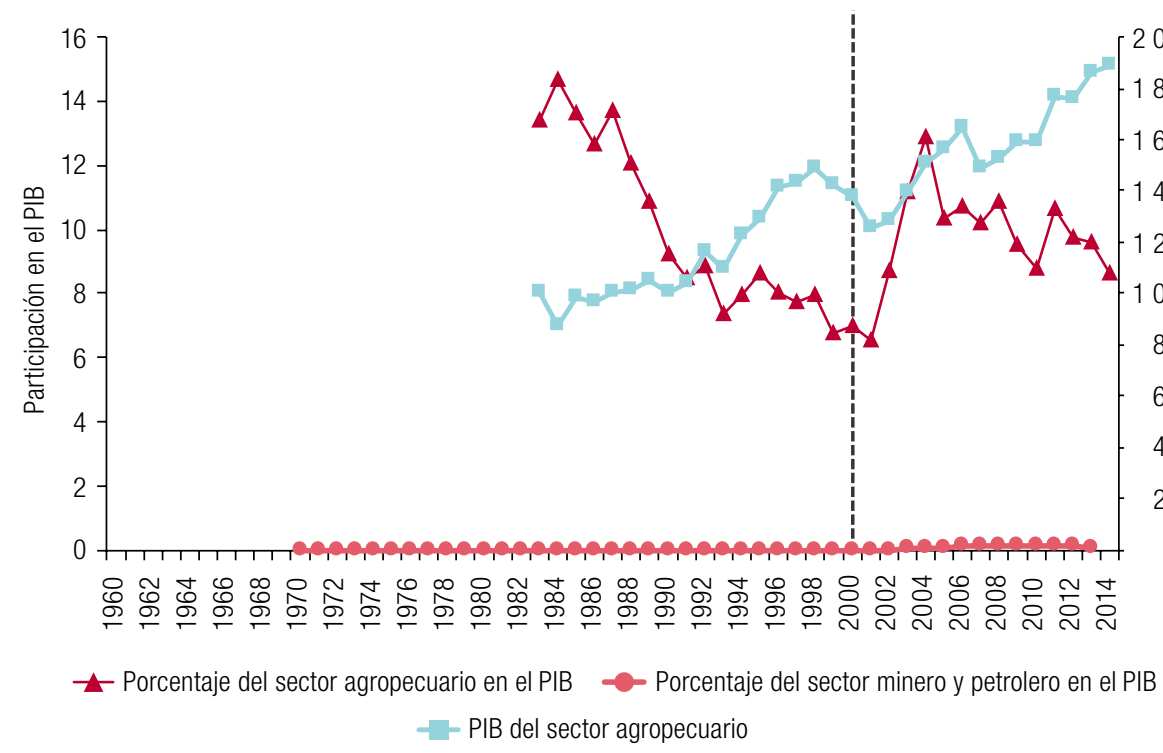

Fuente: Elaboración propia, sobre la base de datos del Banco Mundial, "World Development Indicators (WDI)" (s/f) [base de datos en línea] http://databank.worldbank.org/data/reports.aspx?source=world-development-indicators. 
En el Uruguay, la participación del sector agropecuario en el PIB fue del 7\% en 2000 y aumentó al 8,6\% en 2014 (véase el gráfico 4). En el Paraguay, esos porcentajes fueron de alrededor del 15\% y el 21\%, respectivamente (véase el gráfico 3). Como se puede ver en el cuadro 4, el auge de los precios de los productos agrícolas entre 2002 y 2007 permitió al Uruguay duplicar su valor de producción agrícola anual entre los períodos 2000-2004 y 2010-2013. En el caso del Paraguay, este aumento fue casi del $90 \%$.

Cabe señalar que los cuatro países mencionados anteriormente forman parte del MERCOSUR. A lo largo de la primera década de este siglo, alrededor del 50\% de todas las exportaciones del Paraguay tenían por destino los países miembros de ese bloque. En el Uruguay, ese porcentaje se situó en torno del 30\% durante el mismo período (Graf y Azevedo, 2013). Se puede concluir que la agropecuaria desempeña un papel importante en las economías de estos cuatro países, en especial en la generación de rentas y en el suministro de productos agrícolas a muchos otros países.

\section{b) Estado Plurinacional de Bolivia, Chile, Ecuador, Perú, Colombia y República Bolivariana de Venezuela}

En los países de este grupo se observa un continuo descenso en la participación de la actividad agropecuaria en el PIB desde la década de 1960, incluso en los años de auge de los precios de los productos básicos agrícolas, entre 2002 y 2007 (excepto en la República Bolivariana de Venezuela). Aun así, el valor agregado bruto del sector creció.

En el caso del Estado Plurinacional de Bolivia (véase el gráfico 5), a pesar de que el valor deflactado del PIB agrícola muestra una tendencia creciente desde 1970, en el período de alza de los precios agrícolas (2002 a 2007) la participación del sector agropecuario en el PIB se redujo, mientras la del sector minero y de hidrocarburos aumentó.

\section{Gráfico 5}

Estado Plurinacional de Bolivia: participación de los sectores agropecuario y minero y petrolero en el producto interno bruto (PIB) y valor agregado del sector agropecuario, 1960-2014

(En porcentajes y millones de dólares de 2005)

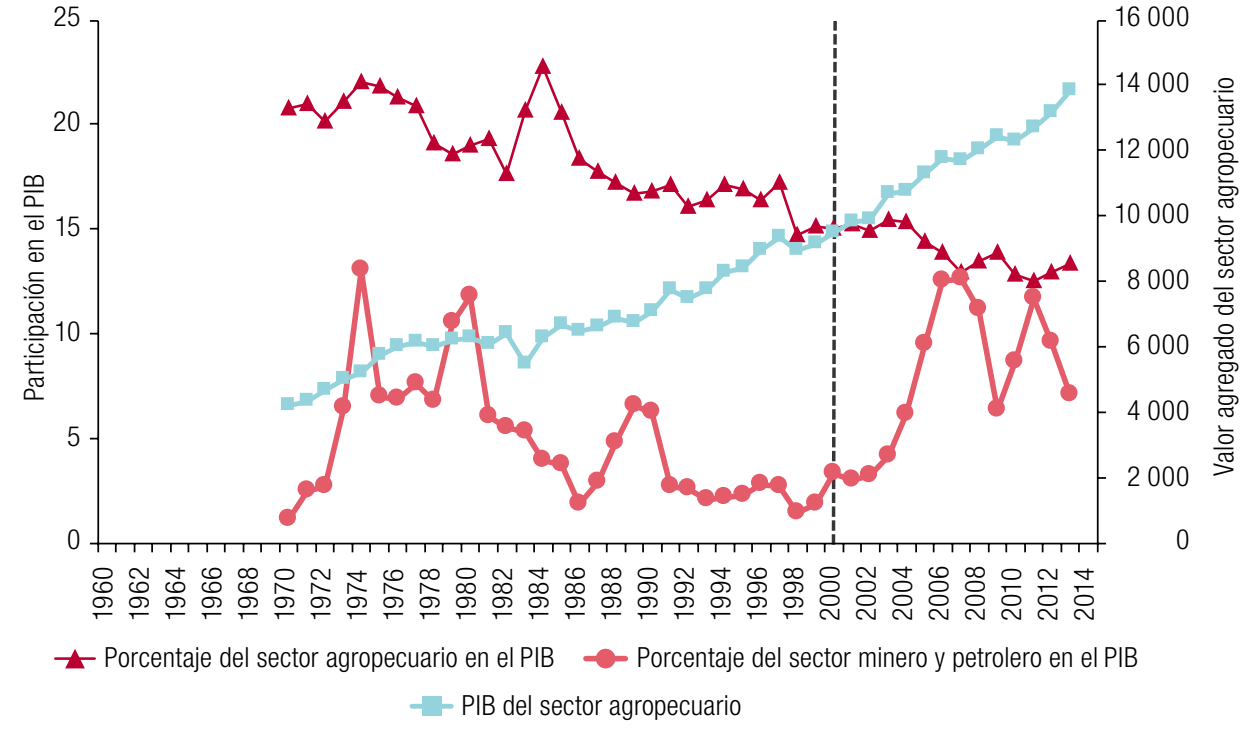

Fuente: Elaboración propia, sobre la base de datos del Banco Mundial, "World Development Indicators (WDI)" (s/f) [base de datos en línea] http://databank.worldbank.org/data/reports.aspx?source=world-development-indicators. 
La situación en Chile (véase el gráfico 6) no difiere mucho de la del Estado Plurinacional de Bolivia. Al contrario de lo que ocurre en países como el Brasil, el clima frío de Chile impide el cultivo de productos tropicales. En el siglo XXI se observa que, a medida que la participación de la actividad agropecuaria en el PIB chileno disminuye, la del sector minero y de hidrocarburos aumenta. En 2014, el VAB de la minería y de hidrocarburos en Chile triplicaba el VAB generado en la agropecuaria.

\section{Gráfico 6}

Chile: participación de los sectores agropecuario y minero y petrolero en el producto interno bruto (PIB) y valor agregado del sector agropecuario, 1960-2014

(En porcentajes y millones de dólares de 2005)

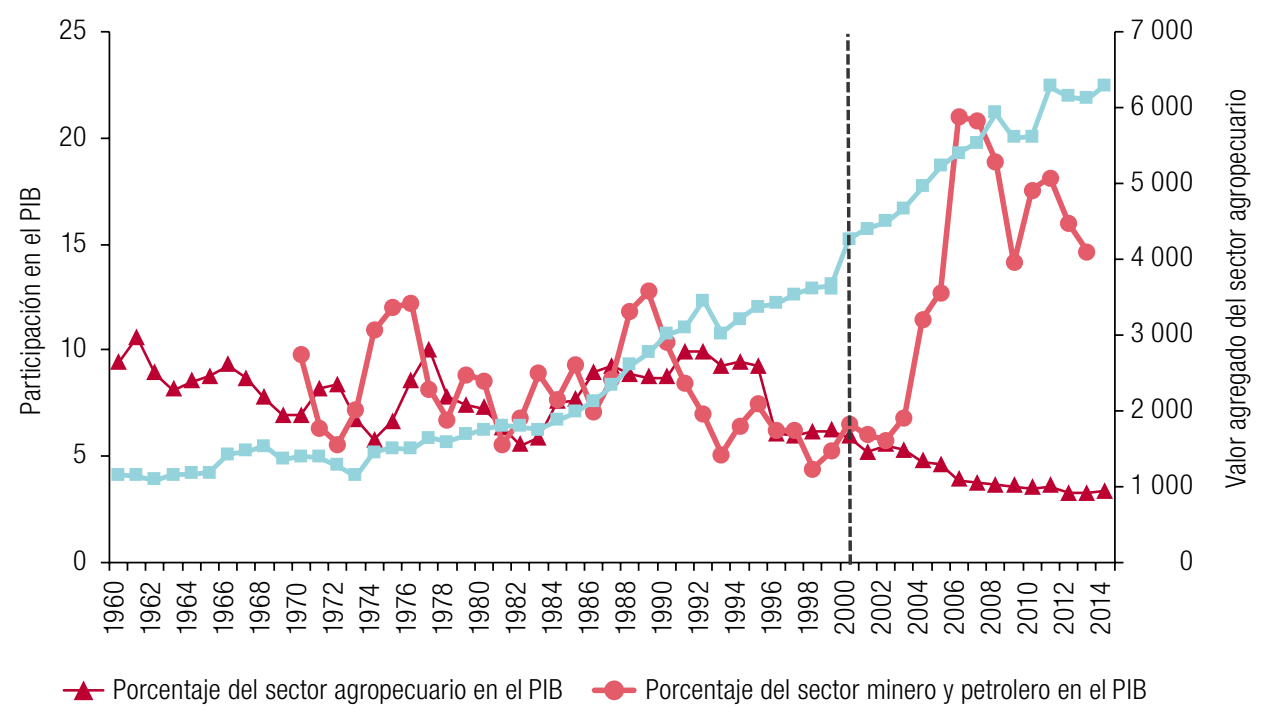

PIB del sector agropecuario

Fuente: Elaboración propia, sobre la base de datos del Banco Mundial, "World Development Indicators (WDI)" (s/f) [base de datos en línea] http://databank.worldbank.org/data/reports.aspx?source=world-development-indicators.

En el Ecuador (véase el gráfico 7), a pesar del considerable aumento en el valor de la producción del sector agropecuario que se registró entre 1960 y 2014, el aporte de este sector al PIB se redujo en gran medida. De acuerdo con Mateo y García (2014) y Tandazo (2012), la participación del sector minero y de hidrocarburos en el PIB ecuatoriano es elevada. La importancia de los hidrocarburos y la minería en la economía ecuatoriana se confirma por el gran crecimiento de su participación en el PIB, que llegó al 25\% en 2008, antes de reducirse a un 20\% en 2012.

De acuerdo con un estudio de la FAO (2006), el Perú también se caracteriza por la baja rentabilidad del sector agropecuario. La principal actividad de uso del suelo peruano es la minería, especialmente la extracción de plata y cobre (Dammert y Molinelli, 2007). En el gráfico 8 se puede observar que la participación de la actividad agropecuaria en el PIB del Perú en 2012, poco más del $5 \%$, es extremadamente baja en comparación con el pasado que evidencia la serie de datos. Por el contrario, la proporción de las rentas de la minería y los hidrocarburos en el PIB peruano se triplicó con creces durante el auge de los precios agrícolas entre 2002 y 2007, al pasar de alrededor del 1,3\% a alrededor del 8\%, respectivamente. 


\section{Gráfico 7}

Ecuador: participación de los sectores agropecuario y minero y petrolero en el producto interno bruto (PIB) y valor agregado del sector agropecuario, 1960-2014

(En porcentajes y millones de dólares de 2005)

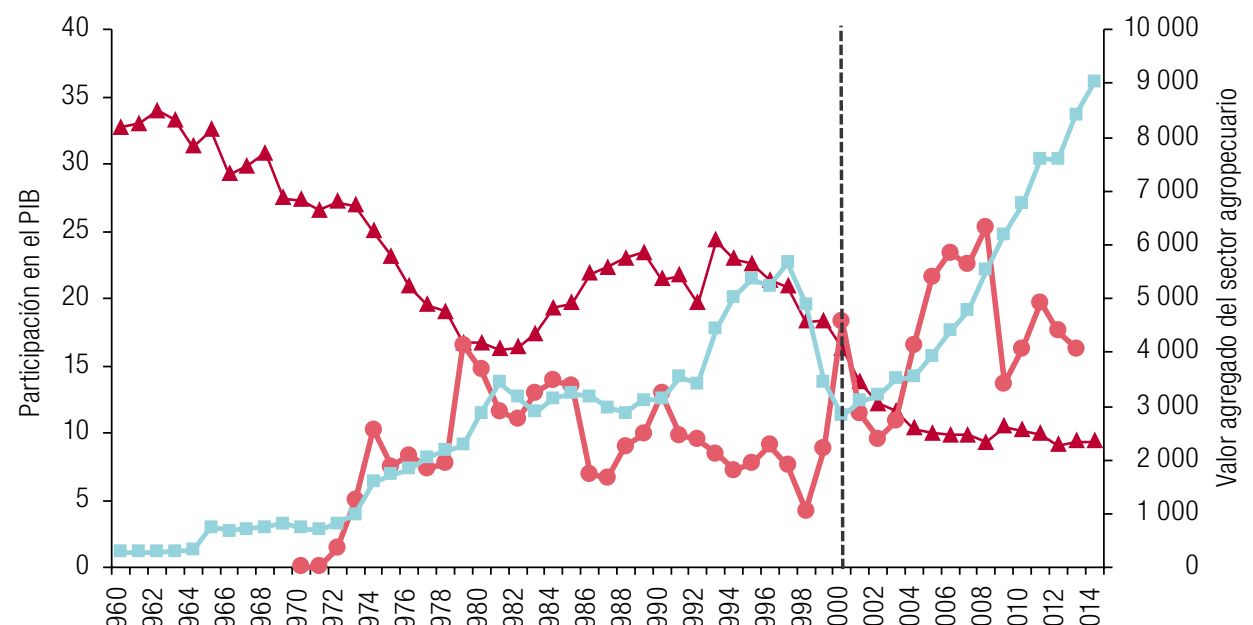

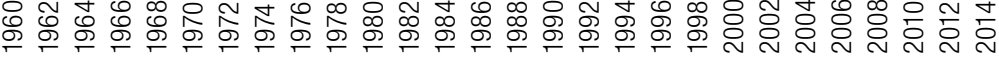

$\_$Porcentaje del sector agropecuario en el PIB - $\quad$ Porcentaje del sector minero y petrolero en el PIB

- PIB del sector agropecuario

Fuente: Elaboración propia, sobre la base de datos del Banco Mundial, "World Development Indicators (WDI)" (s/f) [base de datos en línea] http://databank.worldbank.org/data/reports.aspx?source=world-development-indicators.

\section{Gráfico 8}

Perú: participación de los sectores agropecuario y minero y petrolero en el producto interno bruto (PIB) y valor agregado del sector agropecuario, 1960-2014

(En porcentajes y millones de dólares de 2005)

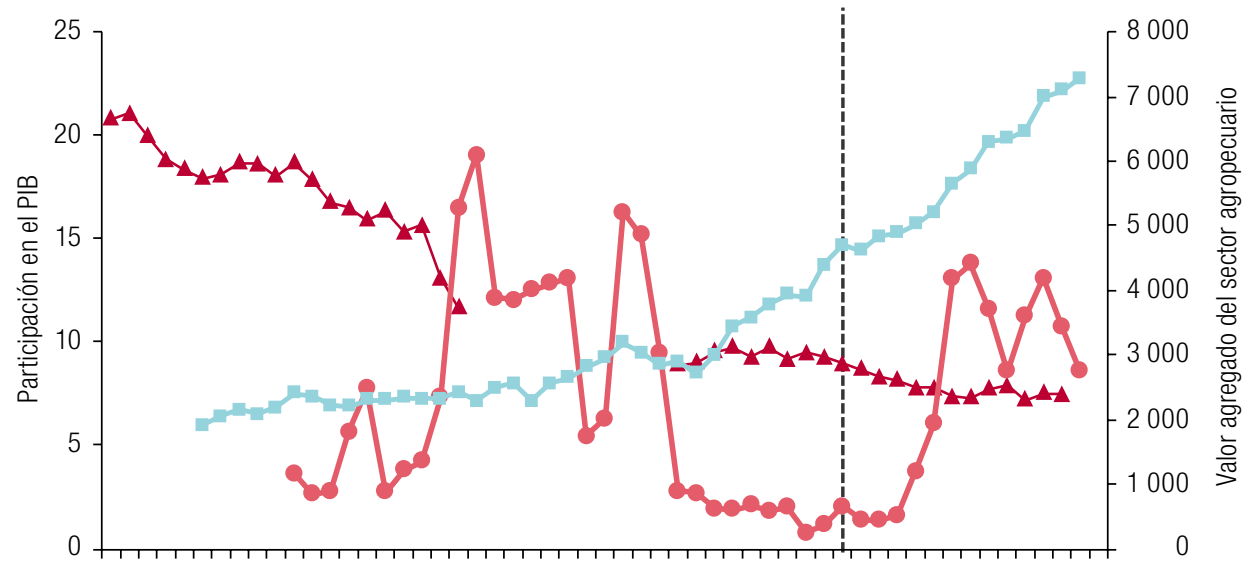

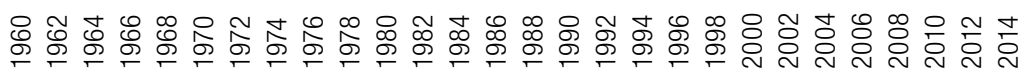

- $\leftarrow$ Porcentaje del sector agropecuario en el PIB - - Porcentaje del sector minero y petrolero en el PIB

\section{- PIB del sector agropecuario}

Fuente: Elaboración propia, sobre la base de datos del Banco Mundial, "World Development Indicators (WDI)" (s/f) [base de datos en línea] http://databank.worldbank.org/data/reports.aspx?source=world-development-indicators. 
Los datos presentados en el gráfico 9 muestran que el valor agregado de la agropecuaria en Colombia en los últimos años sigue siendo igual a los valores observados a principios de la década de 1990. Además, mientras el porcentaje del sector agropecuario en el PIB colombiano ha disminuido, el porcentaje correspondiente a la minería y los hidrocarburos ha aumentado. Parece entonces que, en este siglo, también Colombia está desarrollando su sector minero. Según Muñoz (2014), desde el final de la década de 1990, el gobierno colombiano ha adoptado políticas para atraer la inversión extranjera directa hacia el sector de la minería.

\section{Gráfico 9}

Colombia: participación de los sectores agropecuario y minero y petrolero en el producto interno bruto (PIB) y valor agregado del sector agropecuario, 1960-2014

(En porcentajes y millones de dólares de 2005)

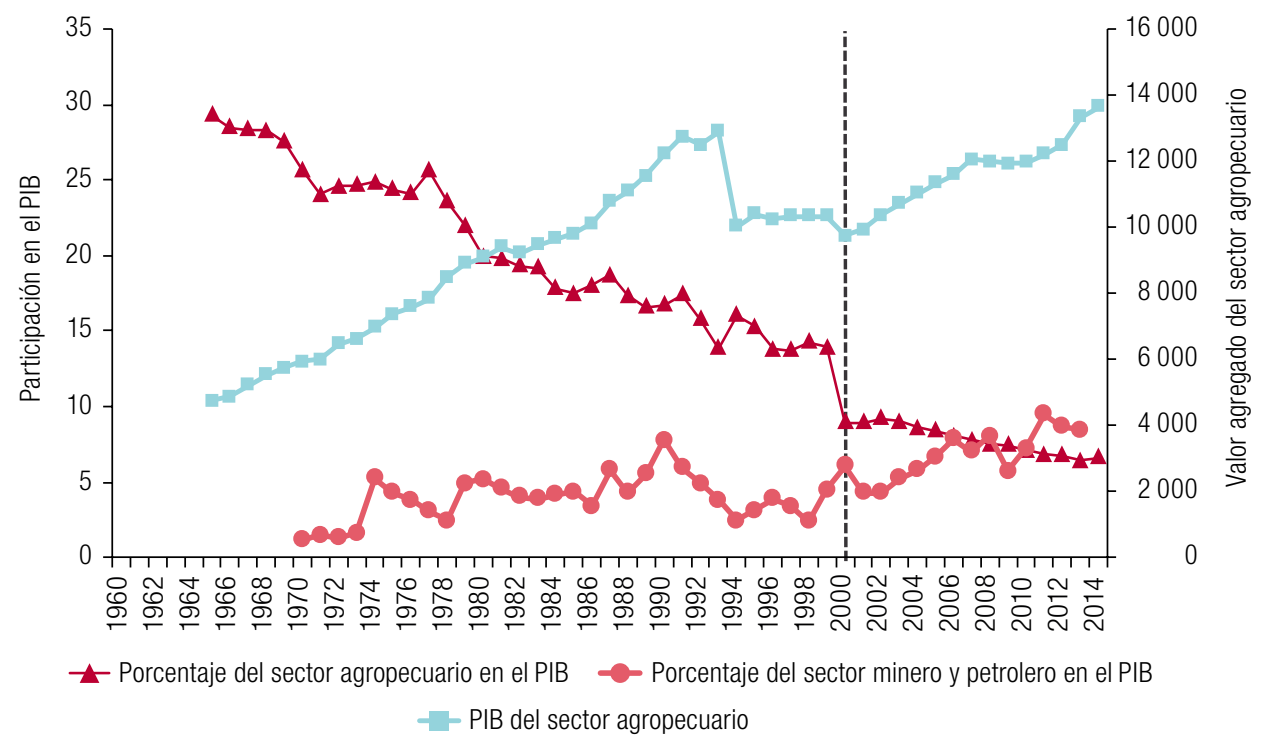

Fuente: Elaboración propia, sobre la base de datos del Banco Mundial, "World Development Indicators (WDI)" (s/f) [base de datos en línea] http://databank.worldbank.org/data/reports.aspx?source=world-development-indicators.

La República Bolivariana de Venezuela se caracteriza por una intensa producción y exportación de petróleo, que constituye un importante sector de su economía desde la década de 1920 (Souza, 2008). Hay un pequeño valor agregado en la agropecuaria y, en consecuencia, su participación en el PIB venezolano también es pequeña, de alrededor del $5 \%$ durante todo el período considerado (véase el gráfico 10). Por otra parte, las rentas derivadas de la producción de petróleo y de la minería oscilan alrededor del 30\% del PIB venezolano en el período de 1970 a 2013. La economía venezolana ha sufrido con las oscilaciones de los precios del barril de petróleo (Bresser-Pereira, 2008) pero debido a la crisis política del gobierno de Maduro no se dispone de datos más recientes. 


\section{Gráfico 10}

República Bolivariana de Venezuela: participación de los sectores agropecuario y minero y petrolero en el producto interno bruto (PIB) y valor agregado del sector agropecuario, 1960-2014 (En porcentajes y millones de dólares de 2005)

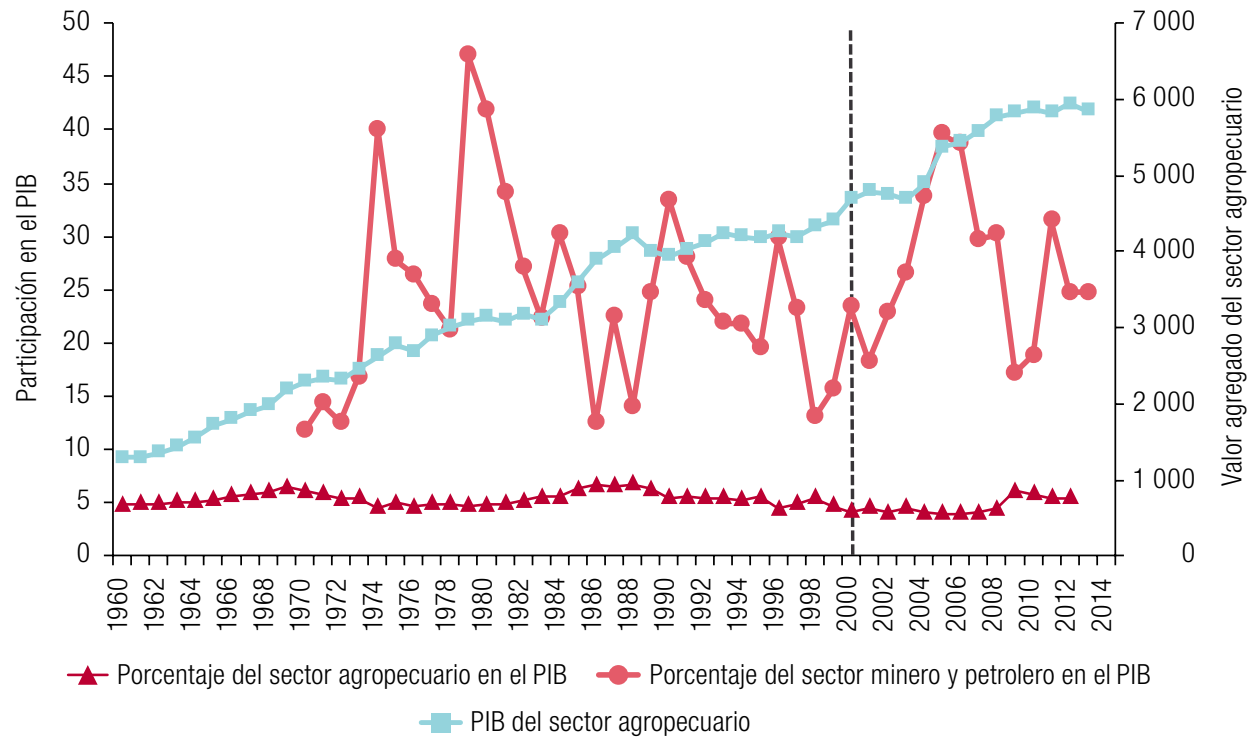

Fuente: Elaboración propia, sobre la base de datos del Banco Mundial, "World Development Indicators (WDI)" (s/f) [base de datos en línea] http://databank.worldbank.org/data/reports.aspx?source=world-development-indicators.

\section{c) Guyana y Suriname}

En los gráficos 11 y 12 se muestra la participación del sector agropecuario y del sector minero y de hidrocarburos en el PIB de Guyana y Suriname, respectivamente. Se observa que el porcentaje del PIB correspondiente a las actividades agropecuarias es mayor en Guyana que en Suriname. A pesar de que la importancia de la agropecuaria como porcentaje del PIB en Guyana aumentó entre 1970 y 1995, esa tendencia se ha debilitado gradualmente desde 1996. Lo mismo sucedió en Suriname, donde el aumento fue significativo solo hasta 1993, fecha a partir de la cual la representatividad de la actividad agropecuaria comenzó a decrecer. Claramente, la serie histórica de la participación agropecuaria en el PIB de Guyana y Suriname presenta una forma de $U$ invertida.

De cualquier modo, la participación del sector agropecuario en el PIB de ambos países fue menor en 2014 que en 1960. Además, la tendencia decreciente de la participación de la agropecuaria en el PIB desde mediados de la década de 1990 fue seguida por un aumento en la participación de la minería y los hidrocarburos.

Debido a que la agropecuaria ocupa menos del 10\% del territorio de Guyana y menos del $1 \%$ del territorio de Suriname (véase el cuadro 1), hay tierras cultivables disponibles para expandir esta actividad en ambos países. Sin embargo, quizás no resulte fácil iniciar dicha expansión dada la falta de una institucionalidad fuerte que garantice dicho proceso. Estos países presentan rezagos en materia de infraestructura, que deben subsanarse. Como repúblicas relativamente jóvenes, también es importante que las dos economías consoliden un sector hegemónico, ya sea agropecuario o no. En ese sentido, y como se puede ver en los gráficos 11 y 12, los sectores que están adquiriendo dicha hegemonía en ambos países son el de la explotación minera y el agropecuario. 


\section{Gráfico 11}

Guyana: participación de los sectores agropecuario y minero y petrolero en el producto interno bruto (PIB) y valor agregado del sector agropecuario, 1960-2014

(En porcentajes y millones de dólares de 2005)

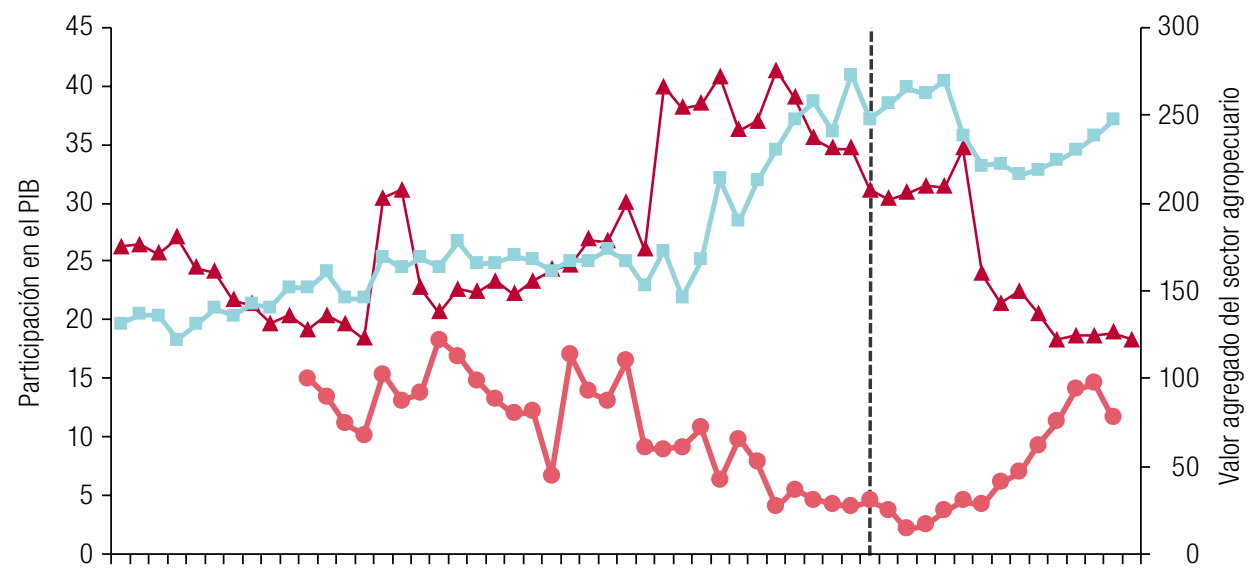

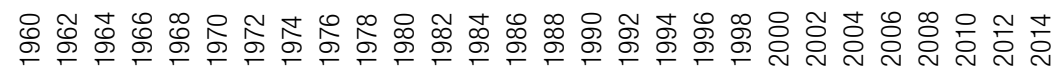

- - Porcentaje del sector agropecuario en el PIB - Porcentaje del sector minero y petrolero en el PIB

- PIB del sector agropecuario

Fuente: Elaboración propia, sobre la base de datos del Banco Mundial, "World Development Indicators (WDI)" (s/f) [base de datos en línea] http://databank.worldbank.org/data/reports.aspx?source=world-development-indicators.

\section{Gráfico 12}

Suriname: participación de los sectores agropecuario y minero y petrolero en el producto interno bruto (PIB) y valor agregado del sector agropecuario, 1960-2014

(En porcentajes y millones de dólares de 2005)

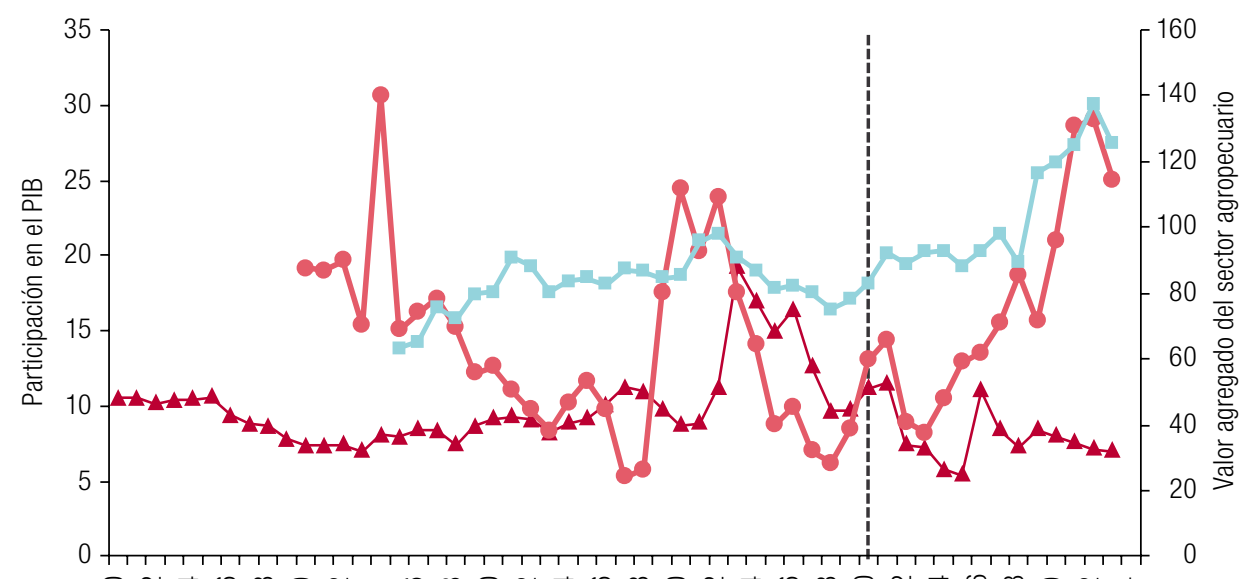

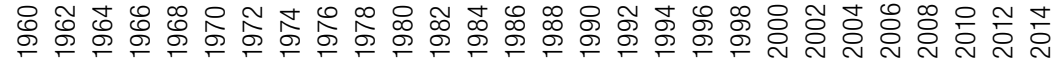

- $\leftarrow$ Porcentaje del sector agropecuario en el PIB - - Porcentaje del sector minero y petrolero en el PIB

- PIB del sector agropecuario

Fuente: Elaboración propia, sobre la base de datos del Banco Mundial, "World Development Indicators (WDI)" (s/f) [base de datos en línea] http://databank.worldbank.org/data/reports.aspx?source=world-development-indicators. 


\section{Conclusiones}

En este artículo se trató de presentar una visión general sobre la compensación entre la producción agropecuaria y la explotación minera y de hidrocarburos en los países de América del Sur. Los resultados de este estudio indican que la agropecuaria es, en general, un sector importante para esta región, aun cuando su participación en el PIB de los países sudamericanos presenta una tendencia constante a la baja. Se observa que, desde 1960, la producción agropecuaria se ha expandido en la mayoría de los países sudamericanos y, al considerar a la región en su conjunto, se aprecia también un superávit comercial agropecuario y agroindustrial. Sin embargo, existen patrones desiguales con respecto a la importancia de la actividad agropecuaria y de la minería y los hidrocarburos en el PIB de cada uno de los países.

La Argentina, el Brasil, el Paraguay y el Uruguay son los miembros fundadores del MERCOSUR y son exportadores netos de productos agropecuarios y agroindustriales. A pesar de que la participación de la minería y los hidrocarburos en el PIB brasileño y argentino ha aumentado, sigue siendo más baja que la participación del sector agropecuario. Por otra parte, la explotación minera y de hidrocarburos no parece ser relevante en el PIB del Paraguay y el Uruguay. Un aspecto importante con respecto a estos cuatro países es el buen desempeño del sector agropecuario en todos ellos durante el auge de los precios agrícolas de 2002 a 2007, que se refleja en el aumento de su contribución al PIB durante ese período.

Las economías del Estado Plurinacional de Bolivia, Chile, el Ecuador, el Perú y la República Bolivariana de Venezuela están más orientadas a la extracción minera y de hidrocarburos que a la actividad agropecuaria. Sus climas y suelos explican parcialmente esta orientación. Aunque la producción agropecuaria aumentó en todos esos países, la participación de este sector en el PIB disminuyó durante todo el período analizado, incluso entre 2002 y 2007. Por otra parte, la participación de la explotación minera y de hidrocarburos en el PIB ha aumentado desde la década de 2000.

Guyana y Suriname son los únicos países en los que la participación del sector agropecuario en el PIB aumentó hasta mediados de la década de 1990, para luego disminuir. A pesar de la disponibilidad de tierra cultivable en ambos países, se presume que la extracción minera y de hidrocarburos crecerá más rápido que la agropecuaria en ambos países. Sin embargo, conviene subrayar que ambos países están dando sus primeros pasos en el actual mundo globalizado, tratando de resolver otros problemas estructurales de la economía que van más allá de la producción y la venta de bienes y servicios.

Los tipos de clima y suelos y la disponibilidad de factores de producción (como la tierra) explican, parcialmente, los hallazgos anteriores y esas potencialidades son debidamente aprovechadas por los inversionistas internacionales. Se define así un patrón de división internacional del trabajo, como se mencionó en la introducción.

\section{Bibliografía}

Acosta, I. (2006), "Balance del modelo agroexportador en América Latina al comenzar el siglo XXl", Mundo Agrario, vol. 7, № 13, La Plata, Universidad Nacional de La Plata.

Bacha, C. (2012), Economia e política agrícola no Brasil, São Paulo, Atlas. (2011), "The evolution of Brazilian agriculture from 1987 to 2009", The Economies of Argentina and Brazil: A Comparative Perspective, W. Baer y D. Fleischer (eds.), Cheltenham, Edward Elgar.

Bacha, C. y L. Carvalho (2014), "What explains the intensification and diversification of Brazil's agricultural production and exports from 1990 to 2012?", IRIBA Working Paper, №2, Manchester, International Research Initiative on Brazil and Africa (IRIBA). 
Bacha, C. y M. Rocha (1998), "O comportamento da agropecuária brasileira no período de 1987 a 1996", Revista de Economia e Sociologia Rural, vol. 36, № 1, Brasilia, Sociedad Brasileña de Economía, Administración y Sociología Rural (SOBER).

Baer, W. (2008), The Brazilian Economy: Growth and Development, Boulder, Colorado, Lynne Rienner.

Banco Mundial (s/f), World Development Indicators (WDI) [base de datos en línea] http://databank.worldbank. org/data/reports.aspx?source=world-development-indicators .

Belloni, P. y A. Wainer (2014), "El rol del capital extranjero y su inserción en la América del Sur posneoliberal", Problemas del Desarrollo, vol. 45, № 177, Ámsterdam, Elsevier.

Boye, G. y W. Ramautarsing (1997), "Revitalizing agriculture in Suriname", Economic and Sector Study Series, $N^{\circ}$ 2, Washington, D.C., Banco Interamericano de Desarrollo (BID).

Bresser-Pereira, E. (2008), "O ouro negro: petróleo e suas crises políticas, econômicas, sociais e ambientais na $2^{a}$ metade do século XX", Outros Tempos, vol. 5, № 6, São Luís, Universidad Estatal de Maranhão.

Bresser-Pereira, L. y N. Marconi (2008), "Existe doença holandesa no Brasil?", ponencia presentada en el IV Foro de Economía de la Fundación Getulio Vargas, São Paulo, marzo.

Brugnaro, R. y C. Bacha (2009), "Análise da participação da agropecuária no PIB do Brasil de 1986 a 2004", Estudos Econômicos, vol. 39, № 1, São Paulo, Universidad de São Paulo.

Cresta, J. y otros (2014), "Sector agroindustrial de Paraguay", Nota Técnica, № 734, Washington, D.C., Banco Interamericano de Desarrollo (BID).

Dammert, A. y F. Molinelli (2007), Panorama de la minería en el Perú, Lima, Organismo Supervisor de la Inversión en Energía y Minería (OSINERGMIN).

FAO (Organización de las Naciones Unidas para la Alimentación y la Agricultura) (s/f), "FAOSTAT" [base de datos en línea] http://faostat3.fao.org.

FAO/CAF (Organización de las Naciones Unidas para la Alimentación y la Agricultura/Corporación Andina de Fomento) (2006), Perú: nota de análisis sectorial. Agricultura y desarrollo rural, Roma.

Fernández, D., J. Piñeros y D. Estrada (2011), "Financiamiento del sector agropecuario: situación y perspectivas", Temas de Estabilidad Financiera, №59, Banco de la República de Colombia.

Foster, W. y E. Jara (2005), "Diversificación de exportaciones agrícolas en América Latina y el Caribe: patrones y determinantes", Economía Agraria, vol. 9, Santiago, Asociación de Economistas Agrarios.

Furtado, C. (1989), Formação Econômica do Brasil, São Paulo, Companhia Editora Nacional.

Graf, C. y A. Azevedo (2013), "Comércio bilateral entre os países membros do MERCOSUL: uma visão do bloco através do modelo gravitacional”, Economia Aplicada, vol. 17, № 1, São Paulo, Universidade de São Paulo.

Guajardo, B. (2007), "La agenda minera en Chile: revisión y perspectivas", serie Recursos Naturales e Infraestructura, № 120 (LC/L.2674-P), Santiago, Comisión Económica para América Latina y el Caribe (CEPAL).

\|lyásova, M. e I. Sérbinov (2015), "China a la conquista de Latinoamérica", RT - SEPA MÁS [en línea] https:// actualidad.rt.com/actualidad/192245-china-inversiones-proyectos-america-latina.

INE (Instituto Nacional de Estadísticas) (2009), Cambios estructurales en la agricultura chilena: análisis intercensal 1976-1997-2007, Santiago.

INE (Instituto Nacional de Estadística) (2009), Uruguay en cifras 2009, Montevideo [en línea] http://www.ine. gub.uy/documents/10181/39317/Uruguay+en+Cifras+09.pdf/13b159a2-19c7-441a-a7ce-86260e527747.

Jales, M. (2005), Inserção do Brasil no comércio internacional agrícola e expansão dos fluxos comerciais sul-sul, Instituto de Estudios do Comercio y Negociaciones Internacionales (ICONE) [en línea] http:// www.lisina.com.br/upload/Inser\%C3\%A7\%C3\%A30\%20do\%20Brasil\%20no\%20Com\%C3\%A9rcio\%20 Internacional.pdf.

Lagos, G. y D. Peters (2010), "El sector minero en Sudamérica”, Working Paper, № 10, São Paulo, Plataforma Democrática [en línea] http://www.plataformademocratica.org/Arquivos/El\%20sector\%20minero\%20 en\%20Sudam\%C3\%A9rica.pdf.

Landa, Y. (2017), "Renta extractiva y la minería del cobre en el Perú", Problemas del Desarrollo, vol. 48, № 189, Ámsterdam, Elsevier.

Lema, D. (1999), "El crecimiento de la agricultura argentina: un análisis de productividad y ventajas comparativas", ponencia presentada en las Primeras Jornadas Interdisciplinarias de Estudios Agrarios y Agroindustriales, Facultad de Ciencias Económicas, Universidad de Buenos Aires, 6-7 noviembre.

Lence, S. (2010), "The agricultural sector in Argentina: major trends and recent developments", The Shifting Patterns of Agricultural Production and Productivity Worldwide, J. Alston, B. Babcock y P. Pardey (orgs.), Ames, lowa, lowa State University. 
Mateo, J. y S. García (2014), "El sector petrolero en Ecuador. 2000-2010”, Problemas del Desarrollo, vol. 45, № 177, Ámsterdam, Elsevier.

Montenegro, D. y A. Guzmán (1999), "Inversión y productividad en el sector agrícola-agroindustrial boliviano: caso de la agricultura comercial período 1985-1998", serie Reformas Económicas, № 43 (LC/L.1288), Santiago, Comisión Económica para América Latina y el Caribe (CEPAL).

Morales, A. (2002), "El sector agrícola y el abastecimiento alimentario en los países exportadores de petróleo: el caso venezolano", Revista Venezolana de Economía y Ciencias Sociales, vol. 8, № 2, Caracas, Universidad Central de Venezuela.

Muñoz, E. (2014), "The dark side of the mining "boom" in Colombia: the open economic mining policies of Colombia's lasts governments have led to internal displacement and harm to the environment by multinational mining companies", tesis para optar al grado de magister, Oslo, Universidad de Oslo.

Oyhantçabal, G. y M. Sanguinetti (2017), "El agro en Uruguay: renta del suelo, ingreso laboral y ganancias", Problemas del Desarrollo, vol. 48, № 189, Ámsterdam, Elsevier.

Pardey, P., S. Wood y R. Hertford (eds.) (2009), Investigaciones a futuro: proyección del potencial agropecuario en América Latina y el Caribe, Washington, D.C., Banco Interamericano de Desarrollo (BID)/Instituto Internacional de Investigación sobre Políticas Alimentarias (IFPRI).

Puyana, A. y A. Constantino (2013), "Sojización y enfermedad holandesa en Argentina: ¿la maldición verde?”, Problemas del Desarrollo, vol. 44, № 175, Ámsterdam, Elsevier.

Reca, L. (2006), Aspectos del desarrollo agropecuario argentino, 1875-2005, Buenos Aires, Academia Nacional de Agronomía y Veterinaria.

Reca, L. y D. Lema (2016), “El consumo de carnes en Argentina 1950-2012”, Desarrollo Económico, vol. 56, № 219, Buenos Aires, Instituto de Desarrollo Económico y Social (IDES).

Romero, Y. (2011), "Incidencia del PIB agropecuario en el PIB nacional: evolución y transformación", Revista Gestión \& Desarrollo, vol. 8, № 2, Bogotá, Universidad San Buenaventura.

Rudas, G. y J. Espitia (2013), "La paradoja de la minería y el desarrollo: análisis departamental y municipal para el caso de Colombia", Minería en Colombia: institucionalidad y territorio, paradojas y conflictos, vol. 2, S. Morelli y L. Garay, Bogotá, Contraloría General de la República de Colombia.

Servín, M. (2011), Desarrollo productivo del Paraguay, Asunción, Centro de Análisis y Difusión de la Economía Paraguaya (CADEP) [en línea] https://mega.nz/\#!RKAkkJSa!VogNaAcrQUtX83YC_ jOAHjX10NYOCpgmfJKH9xP2OTM.

Silva, J., S. Gómez y R. Castañeda (2012), “'Boom’ agrícola e persistência da pobreza na América Latina: algumas reflexões", Revista Nera, vol. 13, № 16, São Paulo, Universidad de São Paulo.

Souza, R. (2008), "O desenvolvimento econômico da Venezuela, 1950/2006", tesis para optar al grado de doctor, Porto Alegre, Universidad Federal de Rio Grande do Sul.

Staritz, C., J. Gold y R. Atoyan (2007), "Guyana: why has growth stopped? An empirical study on the stagnation of economic growth", IMF Working Papers, № 86, Washington, D.C., Fondo Monetario Internacional (FMI).

Tandazo, T. (2012), La actividad económica del Ecuador: una visión desde la economía espacial. Informe de coyuntura económica, №11, Loja, Universidad Técnica Particular de Loja.

Urioste, G. (2009), El sector agropecuario, La Paz, Unidad de Análisis de Políticas Sociales y Económicas (UDAPE).

Valdés, A. y W. Foster (2011), "Latin America's "new open regionalism" and WTO negotiations: the case of agriculture", Economía Agraria y Recursos Naturales, vol. 6, № 12, Valencia, Asociación Española de Economía Agraria.

Visentini, P. (2010), "Guiana e Suriname: uma outra América do Sul", Conjuntura Austral, vol. 1, № 1, Porto Alegre, Universidad Federal de Rio Grande do Sul.

Zarrilli, A. (2013), "The La Plata basin: rivers, plains, and societies in the Southern Cone", RCC Perspectives, № 7, Munich, Rachel Carson Center. 